\title{
Desenvolvimento de compósitos poliméricos reforçados com fibra da folha do buriti
}

\author{
Development of polymeric composites \\ reinforced with buriti leaf fiber
}

\author{
Warley Augusto Pereira ${ }^{1}$, Igor Ceron ${ }^{1}$, Matheus Souza e Silva ${ }^{1}$, \\ Marcos Paulo Chaves de Freitas ${ }^{1}$, Edson Roberto da Silva ${ }^{1}$, \\ Fabíola Medeiros da Costa ${ }^{1}$.
}

\footnotetext{
${ }^{1}$ Faculdade de Engenharia Mecânica, UniRV, Fazenda Fontes do Saber, CEP: 75901-970, Rio Verde, Goiás, Brasil. e-mail: warley@unirv.edu.br, igor.ceron@hotmail.com, matheussouza9616@gmail.com, marcospaulo97_mp@outlook.com,edsonroberto@unirv.edu.br, famedeiroscosta@hotmail.com
}

\begin{abstract}
RESUMO
O objetivo desta pesquisa foi estudar a viabilidade, com relação à resistência à tração, da utilização da folha de buriti como reforço em compósitos com fibras contínuas unidirecionais em matriz polimérica. Como matriz, foram utilizadas as resinas de poliéster isoftálico, de poliéster ortoftálico e de epóxi. Analisou-se a resistência à tração da fibra, das resinas e dos compósitos confeccionados com cada polímero. Testes de arrancamento foram realizados para verificar a adesão da fibra nas resinas usadas como matriz. Foi feita uma caracterização da fibra através de microscopia óptica e com microscópio eletrônico de varredura (MEV), além da determinação de sua densidade. Quanto à estrutura, observou-se que as fibras possuem uma lacuna central entre as faces adaxial e abaxial e que há um enrolamento da fibra. Os ensaios de arrancamento mostraram que houve maior adesão entre a fibra da folha de buriti e a matriz de epóxi, com um comprimento crítico $l c=$ $1,0 \mathrm{~mm}$, seguido pela matriz de poliéster isoftálico, com $l c=2,8 \mathrm{~mm}$, e pela matriz de poliéster ortoftálico, $\operatorname{com} l c=26,8 \mathrm{~mm}$. A fibra apresentou resistência à tração variando entre 100,8 MPa e 224,1 MPa. Verificouse que a resistência à tração das fibras é maior para diâmetros menores. Entre as resinas estudadas, a de epóxi foi a que apresentou maior resistência média à tração $(60,5 \mathrm{MPa})$, seguido pela de poliéster isoftálico $(34,5$ $\mathrm{MPa})$ e pela de poliéster ortoftálico $(27,7 \mathrm{MPa})$. Testes com os compósitos criados mostraram que a matriz de epóxi é a mais promissora quanto à resistência à tração, seguida pela matriz de poliéster isoftálico. A matriz de poliéster ortoftálico apresentou valores de resistência bem abaixo da demais. Conclui-se que a fibra da folha de buriti apresentou um bom potencial para a produção de compósitos leves e resistentes.
\end{abstract}

Palavras-chave: Ensaio de arrancamento. Resistência à tração. Densidade. Matriz polimérica. Fibra vegetal.

\section{ABSTRACT}

The objective of this research was to study the viability, with respect to tensile strength, of using buriti leaf as reinforcement in composites with unidirectional continuous fibers in polymeric matrix. As matrix, isophthalic polyester, orthophthalic polyester and epoxy resins were used. The tensile strength of fiber, resins and composites confectioned with each polymer was analyzed. Pullout tests were performed to verify fiber adhesion with the resins used as matrix. The fiber was characterized by optical microscopy and using a scanning electron microscope (SEM) in addition to determining its density. Regarding the structure, it was observed that the fibers have a central gap between the adaxial and abaxial faces and that there is a winding of the fiber. The pullout tests showed that there was greater adhesion between the buriti leaf fiber and the epoxy matrix, with a critical length $l c=1.0 \mathrm{~mm}$, followed by the isophthalic polyester matrix, with $l c=2.8 \mathrm{~mm}$, and the matrix of orthophthalic polyester with $l c=26.8 \mathrm{~mm}$. The fiber presented tensile strength ranging from 100.8 $\mathrm{MPa}$ to 224.1 MPa. It was found that the tensile strength of the fibers is higher for smaller diameters. Among the resins studied, epoxy showed the highest average tensile strength $(60.5 \mathrm{MPa})$, followed by isophthalic polyester (34.5 MPa) and orthophthalic polyester (27.7 MPa). Tests with the composites created showed that 
the epoxy matrix is the most promising as tensile strength, followed by the isophthalic polyester matrix. The orthophthalic polyester matrix presented resistance values much below the others. It was concluded that the buriti leaf fiber presented a good potential for the production of light and resistant composites.

Keywords: Pullout test. Tensile strength. Density. Polymeric matrix. Vegetable fiber.

\section{INTRODUÇÃO}

Novos compósitos de matriz polimérica reforçados com fibras vegetais vêm sendo desenvolvidos, principalmente nas últimas duas décadas, devido à grande quantidade e variedade deste tipo de fibra encontrada na natureza $[1,2]$. As fibras vegetais lignocelulósicas normalmente possuem baixa densidade, proporcionando uma alta relação resistência/peso, são porosas, não são abrasivas, possuem viscoelasticidade, são biodegradáveis, além de serem obtidas de fontes renováveis [3]. O aumento da popularidade dos compósitos poliméricos reforçados com fibras naturais se deve ao seu destino não perigoso e ao processo de fabricação econômico. As aplicações de tais compósitos têm aumentado rapidamente desde as últimas duas décadas como substituto potencial dos materiais à base de fibra sintética em diversos campos dos setores de engenharia, incluindo automotivo, aeroespacial, marítimo, construção avançada, dispositivo de armazenamento de energia e até mesmo em materiais biomédicos [4].

Planta tipicamente da floresta amazônica e cerrado, o buriti (Mauritia flexuosa) é uma das palmeiras mais abundantes do país. Do buriti são utilizados os frutos, o caule e as folhas, com aplicações em confecções de artigos de artesanato, indústria farmacêutica, alimentícia entre outros. Sua folha é muito utilizada na confecção de cordas muito fortes para uso no campo.

Alguns estudos foram realizados em compósitos poliméricos reforçados com fibras extraídas da folha do buriti, obtendo resultados satisfatórios de resistência à temperatura (até $250^{\circ} \mathrm{C}$ ) em matriz de epóxi [5], além de resistência à tração e ao impacto [6,7]. Entretanto, diferente das pesquisas citadas, onde as fibras foram retiradas do pecíolo das folhas (região central e mais rígida das folhas), no presente estudo foi utilizado o limbo (ou lâmina), que é a parte mais flexível da folha. Quando seco, o limbo tem aspecto de palha e produz fibras mais flexíveis e mais leves que aquelas produzidas pelo pecíolo, com potencial para produção de compósitos com estas características. Porém, é necessário primeiramente o conhecimento de seu comportamento mecânico, para que se possa definir a viabilidade de seu uso como reforço em compósitos.

Tanto polímeros termoplásticos como os termofixos são usados como matriz em compósitos de fibras vegetais, sendo os termofixos os mais comuns. Entre os polímeros termofixos, os mais utilizados como matriz neste tipo de compósito são os poliésteres, os epóxis e os fenólicos. A maior vantagem dos polímeros termofixos é que eles têm uma viscosidade muito baixa e podem ser introduzidos nas fibras a baixas pressões. Os termofixos são processados por técnicas simples, como operações de moldagem e pulverização manual, compressão, transferência, injeção, prensagem a frio, enrolamento filamentar, pultrusão, moldagem a vácuo, entre outras. Os compósitos reforçados com fibras naturais usando kenaf, fibra de coco, banana, sisal, juta, linho e folha de abacaxi mostraram melhores propriedades mecânicas com uma matriz termofixa, tornandoos atraentes em aplicações de transporte de baixa carga, incluindo móveis, embalagens de alimentos e aplicações automotivas. Além disso, suas características mecânicas, sua boa capacidade de adesão a vários tipos de fibras vegetais e baixo teor de umidade são características consideradas na escolha das resinas termofixas [8]. Outra vantagem dos polímeros termofixos é a possibilidade de serem processados em baixas temperaturas, diferente dos termoplásticos que, em sua maioria, são processados em altas temperaturas, o que poderia causar danos às fibras vegetais [9].

Um dos fatores que mais influenciam nas propriedades mecânicas dos compósitos é a adesão entre os dois componentes. A adesão fibra/matriz atua diretamente sobre as propriedades mecânicas e químicas do material criado. Isso ocorre porque, havendo uma boa interação entre os dois materiais constituintes, as fibras transmitem à matriz sua alta resistência à tração [10]. Contudo, em compósitos com fibras vegetais, suas propriedades mecânicas podem ser prejudicadas devido à natureza hidrofílica destas fibras e à natureza hidrofóbica da matriz polimérica, podendo promover uma fraca ligação de interface entre os dois componentes [11].

A falha de um compósito depende de mecanismos diferentes. Quando o esforço aplicado excede a força de interface, ocorrerão descolamento e arrancamento da fibra. Através de forças de atrito, a tensão ainda pode ser transferida para uma fibra ao longo da interface, pela qual a energia é absorvida. Esse tipo de adesão fibra/matriz é chamado de resistência aparente ao cisalhamento interfacial. Se as forças aplicadas são maiores que a força da fibra local, a fibra falha devido à tensão [12].

Para a interpretação das propriedades mecânicas de um compósito, a caracterização da adesão entre a fibra/matriz é de especial importância. Para a análise de compósitos convencionais, como compósitos refor- 
çados com fibra de vidro ou carbono, alguns ensaios estão disponíveis, sendo o de arrancamento (pullout test) um dos mais aplicados para determinar a tensão necessária para quebrar a interface fibra/matriz do compósito [3, 12-16]. Segundo MONTEIRO e D'ALMEIDA [16], os ensaios de arrancamento visam determinar o comprimento crítico da fibra $(l c)$, e a tensão cisalhante interfacial $(\tau)$, associada à transferência de esforços entre a fibra e a matriz de um compósito. Neste tipo de ensaio a matriz é fixada e a fibra é puxada, no sentido longitudinal.

Devido às características citadas das fibras da folha do buriti, esta pesquisa teve como objetivo realizar um estudo da viabilidade, com relação à resistência à tração e à capacidade de adesão em polímeros, da utilização destas folhas como reforço em compósitos com fibras contínuas e unidirecionais em matriz polimérica. Como objetivo secundário, selecionar uma resina polimérica mais compatível com a fibra, para gerar compósitos mais resistentes. Neste estudo, verificaram-se as resistências individuais da fibra e das resinas usadas como matriz, além da resistência dos compósitos criados com cada matriz. Também foi testada a adesão entre a fibra e a matriz a fim de se determinar o par mais promissor para a produção de um novo compósito.

\section{MATERIAIS E MÉTODOS}

A metodologia da pesquisa foi dividida em três etapas. A primeira etapa foi a preparação e a caracterização das fibras através da visualização de sua estrutura por microscopia óptica e por MEV, além da determinação de sua densidade. A segunda etapa foi a confecção dos corpos de prova para ensaios mecânicos. A terceira etapa foi a própria realização dos ensaios mecânicos. Os ensaios mecânicos foram realizados para verificar a resistência à tração das fibras (fio único) e da matriz polimérica, separadamente, e dos compósitos produzidos. Os testes de arrancamento foram realizados para verificar a adesão entre a fibra e a matriz, com o intuito de se poder escolher o melhor par fibra/matriz entre as resinas analisadas.

\subsection{Materiais}

As fibras utilizadas para o desenvolvimento desta pesquisa foram retiradas do limbo das folhas do buriti. Para as matrizes poliméricas foram usados três tipos diferentes de resina termofixa para a produção dos compósitos, sendo elas: resina de poliéster cristal - Arazyn 1.0\#00 (resina de poliéster insaturada, ortoftálica) com catalizador Butanox M-50; resina de poliéster insaturada isoftálica UC ISO 1014 BB, com catalizador Butanox M-50, ambas as resinas com diluição de 1\% em massa do catalizador; resina epóxi 2001 PT com endurecedor epóxi 3154BB, com diluição de $100 \%$ de resina para 50\% de endurecedor em massa, conforme orientação do fabricante. Todas as resinas e catalizadores usados são da marca Redelease. As composições das misturas (resina/endurecedor) seguiram as especificações do fabricante.

\subsection{Processamento e caracterização das fibras}

Para a obtenção das fibras, as folhas de buriti foram secas naturalmente por seis meses em local coberto e ventilado. A seguir foi feito o desfiamento manual das folhas. Devido à dificuldade de se manter um padrão no diâmetro das fibras, estas foram desfiadas com um diâmetro médio variando entre $0,15 \mathrm{~mm}$ a $0,96 \mathrm{~mm}$. As fibras foram cortadas com comprimentos de $250 \mathrm{~mm}$ e as medidas dos diâmetros médios foram realizadas em três pontos ao longo do comprimento de cada fibra (Figura 1a), por um sistema de aquisição de imagens composto pelo microscópio Estereoscópio Trinocular com Zoom - Nova XTD 30, com ampliação de 20X, e uma câmera digital colorida 1.3 MP com software BEL Capture V3.0 - Modelo - TA-0124-A - OPTON. Os diâmetros médios calculados a partir das medidas foram usados para se determinar a área média da seção transversal das fibras para os ensaios de tração destas, sendo que para estes ensaios foram medidos os diâmetros de trinta amostras da fibra.

Com o mesmo sistema de aquisição de imagens, foi possível observar o corte da seção transversal de uma das fibras, conforme mostrado na Figura $1 \mathrm{~b}$. 

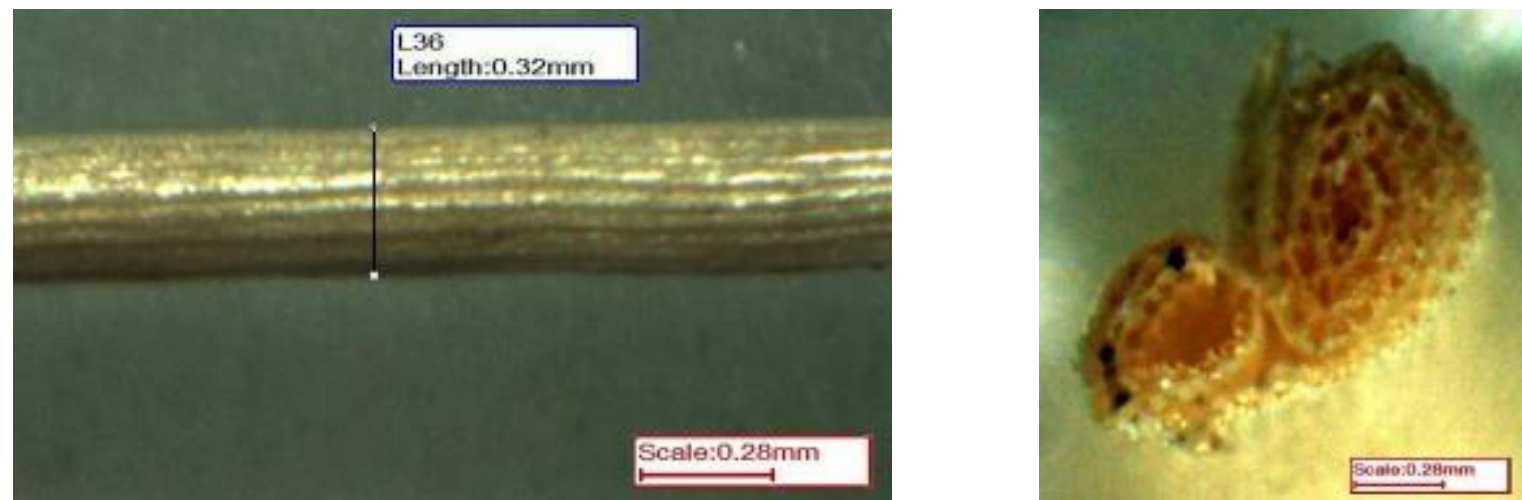

Figura 1: Fibra da folha de buriti (Ampliação 20x). (a) Medida do diâmetro da fibra; (b) corte da seção transversal.

Para caracterização das fibras e da superfície de fratura das amostras foi feita uma caracterização por MEV, utilizando-se um microscópio eletrônico de varredura JEOL JSM-IT300LV, operando em baixo vácuo no modo de detecção de elétrons retroespalhados, com tensão de aceleração de elétrons de $15 \mathrm{kV}$. A Figura 2a mostra o aspecto da superfície da fibra e a Figura $2 b$ mostra o corte de sua seção transversal.
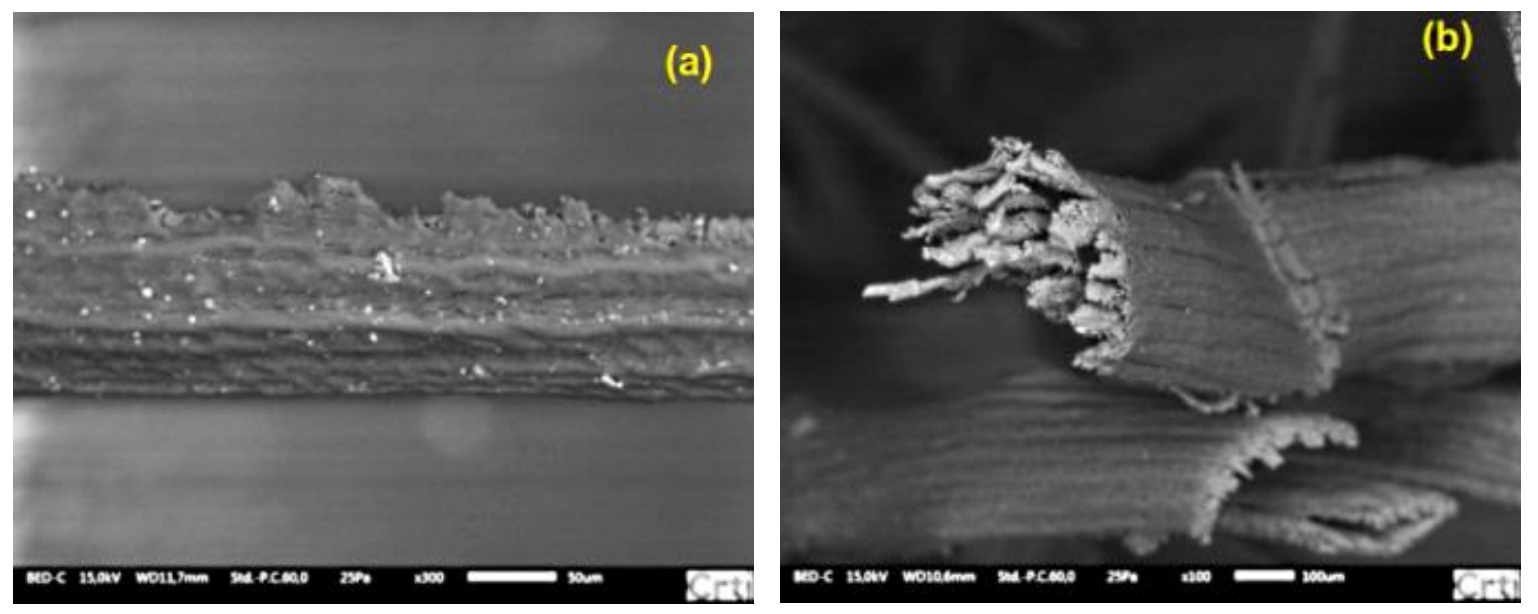

Figura 2: Fibra da folha de buriti: (a) superfície longitudinal (300x); (b) seção transversal (100x).

Para a determinação da densidade da fibra, utilizou-se o método de Arquimedes. As quatro amostras analisadas foram pesadas em uma balança semianalítica BEL Engeneering, $310 \mathrm{~g}$, modelo L303i $( \pm 0,001 \mathrm{~g})$. Para a determinação do volume das fibras utilizou-se o método de imersão destas em água destilada em temperatura ambiente $\left(\approx 25^{\circ} \mathrm{C}\right)$ em uma proveta graduada e fechada com filme plástico para evitar evaporação da água até que a fibra afundasse completamente na água. Depois disto, verificou-se o volume de água deslocado, e as densidades foram calculadas. Foram usadas quatro amostras e calculada a média dos valores obtidos.

\subsection{Processamento e caracterização dos polímeros e dos compósitos}

Para a determinação das densidades das resinas e dos compósitos produzidos para as análises, os corpos de prova de seção retangular foram pesados na mesma balança citada e foram feitas as medidas da largura, comprimento e espessura com um paquímetro para determinar o volume e, a seguir, calculou-se as densidades. Foram usados oito corpos de prova de cada material e obtida uma média das medidas.

Os corpos de prova para testar a resistência das resinas foram feitos em molde metálico com 3,5 mm de espessura, $25 \mathrm{~mm}$ de largura e $300 \mathrm{~mm}$ de comprimento, depois os corpos de prova foram usinados para ficarem de acordo com o modelo Tipo I, indicado para corpos de prova com espessura menor que 7,0 $\mathrm{mm}$ pela norma ASTM D638-14 [17], conforme apresentado na Figura 3. 


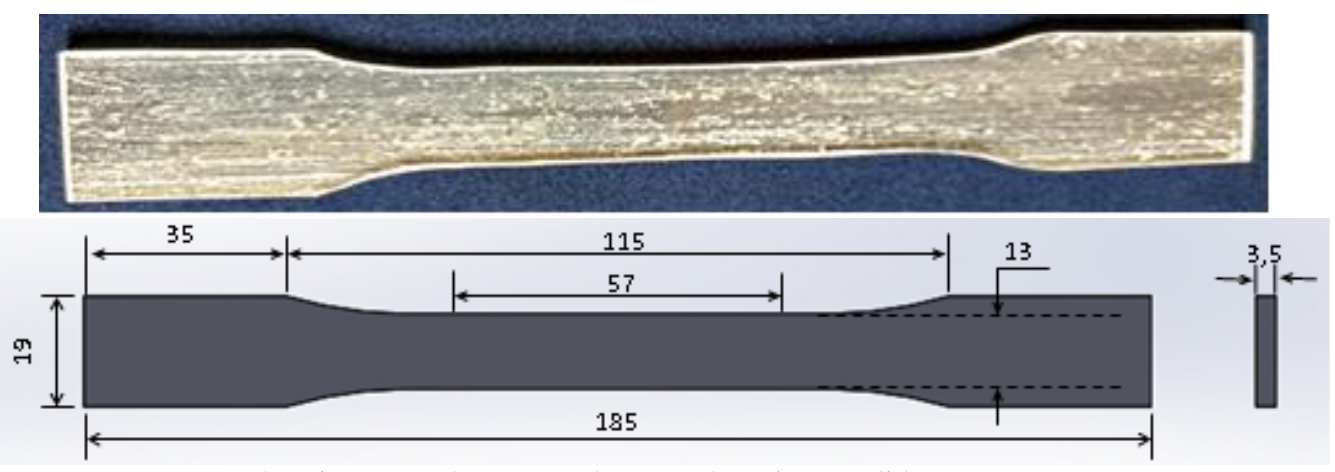

b) Dimensões dos corpos de prova de resina (medidas em $\mathrm{mm}$ )

Figura 3: Corpos de prova dos polímeros usados nos ensaios de tração.

Para os corpos de prova do compósito, utilizou-se um molde de borracha de silicone, onde foi feita a laminação do compósito, formando uma placa. Esta laminação foi feita alternando-se camadas de resina e de fibras soltas, procurando-se manter as fibras alinhadas no sentido longitudinal do molde. Posteriormente, a placa obtida foi cortada para confeccionar os corpos de prova de seção retangular, de acordo com a norma ASTM D3039 [18]. As dimensões finais desses corpos de prova foram: $250 \mathrm{~mm}$ de comprimento, $20 \mathrm{~mm}$ de largura e $5 \mathrm{~mm}$ de espessura (Figura 4).

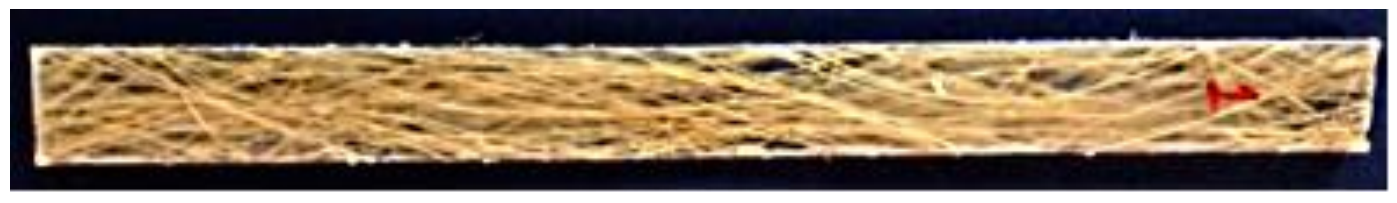

Figura 4: Corpos de prova dos compósitos para os ensaios de tração.

Foram preparados e ensaiados cinco corpos de prova para cada tipo de resina usada e cinco para cada tipo de compósito, de acordo com a resina usada, que é uma quantidade suficiente para ensaios mecânicos, de acordo com as normas citadas.

\subsection{Ensaios de Arrancamento (pullout tests)}

Nos ensaios de arrancamento (pullout test), para testar a adesão entre as fibras e a matriz polimérica, foi utilizada plastilina para a confecção dos moldes. A plastilina foi perfurada por uma caneta esferográfica, deixando um espaço vazio para enchimento com a resina. A seguir foi colocada uma das pontas da fibra dentro da resina, e quando esta endureceu formou uma cápsula de resina com uma das pontas da fibra embutida. $\mathrm{O}$ comprimento total das fibras antes do embutimento foi de $250 \mathrm{~mm}$. Esse procedimento foi realizado para os três tipos de resina (poliéster ortoftálico, poliéster isoftálico e epóxi). A Figura 5 mostra um corpo de prova típico para o ensaio de arrancamento.

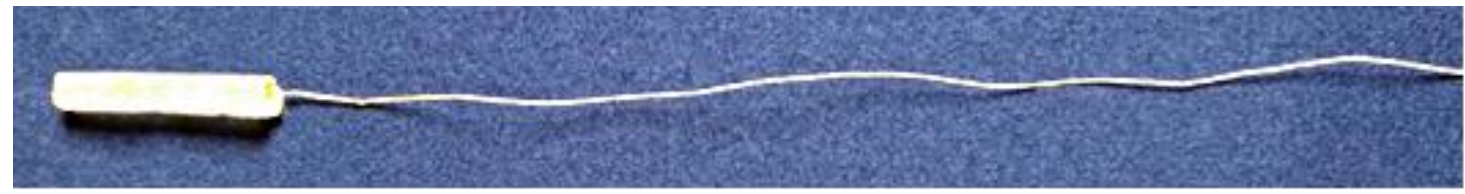

Figura 5: Corpo de prova para ensaio de arrancamento (pullout test).

Os ensaios de arrancamento (pullout tests) foram realizados de acordo com a metodologia proposta por MONTEIRO e D'ALMEIDA [16]. Na execução dos ensaios de arrancamento foi utilizada a máquina universal de ensaios, modelo BME-20kN da Oswaldo Filizola com software DynaView. Nestes ensaios, a ponta livre da fibra (não embutida) foi fixada na garra da máquina, sendo protegida por uma borracha para que a garra não cortasse a fibra. A outra extremidade do corpo de prova, com a cápsula de resina, foi fixada na ou- 
tra garra e depois tracionada, verificando-se, para cada comprimento de embutimento da fibra na resina, se houve arranchamento da fibra sem sua ruptura, ou se a fibra se rompia fora da cápsula de resina, sem escorregamento. Foram realizadas quatro réplicas para cada profundidade de embutimento.

Nos três tipos de resina, o embutimento começou com $5 \mathrm{~mm}$ de profundidade e feitos os testes de arrancamento até que houvesse ruptura da fibra ou escorregamento desta. Quando houve escorregamento, os embutimento seguintes eram feitos com profundidades maiores (a partir de $5 \mathrm{~mm}$ ), aumentando-se esse valor até que se obtivesse ruptura da fibra sem escorregamento. Nos casos onde houve ruptura das fibras com a profundidade inicial de $5 \mathrm{~mm}$, os embutimentos seguintes foram feitos com 3,2 e até $1 \mathrm{~mm}$ de profundidade, até que houvesse escorregamento da fibra na resina. Para se determinar a área da seção transversal das fibras, foi usada a mesma metodologia utilizada para se medir o seu diâmetro médio, como descrito anteriormente.

Após os ensaios de arrancamento, determinou-se graficamente o comprimento crítico da fibra $(l c)$ e a tensão cisalhante interfacial $\left(\tau_{c}\right)$ para cada par fibra/resina, utilizando a Equação (1), mais indicada para compósitos poliméricos reforçados com fibras lignocelulósicas, devido à natureza hidrofílica da fibra e hidrofóbica da matriz polimérica [16].

$$
\tau_{c}=\frac{r \sigma_{f}}{2 l_{c}}
$$

Onde $r$ é o raio médio das fibras e $\sigma_{f}$ sua resistência à tração.

\subsection{Caracterização mecânica - ensaios de tração}

Nesta etapa, foram realizados os ensaios de tração para verificar a resistência das fibras e da matriz polimérica, separadamente, e dos compósitos produzidos.

Para os ensaios de tração das fibras, utilizou-se a máquina universal de ensaios modelo BME-20KN da marca Oswaldo Filizola com software DynaView, onde se prendeu cada uma de suas pontas em uma das garras da máquina, protegidas por borrachas para que não houvesse esmagamento ou ruptura das fibras dentro da garra da máquina ou fora do comprimento útil da fibra, inutilizando o ensaio. Em seguida, realizou-se o tracionamento das fibras até sua ruptura, obtendo-se seu limite de resistência à tração, limite de escoamento, módulo de elasticidade e deformação na ruptura.

Por fim, foram realizados os ensaios de tração dos corpos de prova das resinas de poliéster ortoftálico e isoftálico e de epóxi, para verificar também as mesmas propriedades mecânicas obtidas para as fibras. Para estes ensaios, utilizou-se uma máquina universal de ensaios Instron Emic 23-300. Esse mesmo equipamento foi utilizado nos ensaios de tração dos corpos de prova dos compósitos criados a partir de cada resina. Em todos os ensaios de tração realizados, inclusive nos ensaios de arrancamento, a velocidade de deslocamento das garras foi de $5 \mathrm{~mm} / \mathrm{min}$.

\section{RESULTADOS}

\subsection{Caracterização dos materiais utilizados}

Através da análise da imagem da seção transversal das fibras da folha do buriti (Figura 1b), verificou-se que as células epidérmicas dos segmentos foliares das faces adaxial e abaxial apresentam uma lacuna central entre estas faces, de formato predominantemente quadrangular e de parede espessada. As fibras vegetais normalmente são ocas, e os espaços vazios são denominados lúmen [19]. PASSOS e MENDONÇA [20], através de análise por MEV na seção transversal das folhas de buriti, verificaram a presença do lúmen, confirmando o que foi observado na Figura 1b. Devido ao fato da folha ser muito fina e com a presença dos lúmens, houve um limite mínimo do diâmetro que se conseguiu extrair a fibra da folha do buriti sem destruí-la, no caso desta pesquisa foi de $0,15 \mathrm{~mm}$. Observou-se ainda que o enrolamento ou encurvamento das fibras, dependendo do diâmetro, sempre ocorreu.

A Figura 2a mostra irregularidades na superfície da fibra, que correspondem aos furos observados na seção transversal das figuras $1 \mathrm{~b}$ e $2 \mathrm{~b}$. DEMOSTHENES et al. [5] afirmam que alguns furos parecem estar associados a uma rede de porosidade e canais de água e nutrientes da planta. Esses canais internos e porosidade, em que alguns orifícios cilíndricos maiores podem ser atribuídos ao lúmen, enquanto que os cilindros pequenos podem estar relacionados às microfibrilas.

A Tabela 1 apresenta a quantidade de fibras e resinas usadas em cada compósito criado e sua fração volumétrica correspondente. Apresenta também as massas dos compósitos desenvolvidos. 
Tabela 1: Propriedades de massa e volume das fibras, dos polímeros e dos respectivos compósitos.

\begin{tabular}{c|c|c|c}
\hline \multirow{2}{*}{ PROPRIEDADES } & \multicolumn{3}{|c}{ RESINA } \\
\cline { 2 - 4 } & ORTOFTÁLICA & ISOFTÁLICA & EPÓXI \\
\hline Massa do Compósito $(\mathrm{g})$ & 334 & 323 & 362 \\
\hline Massa Fibra $(\mathrm{g})$ & 9,567 & 9,929 & 352,361 \\
\hline Massa da resina $(\mathrm{g})$ & 324,433 & 313,071 & 25,366 \\
\hline Volume da fibra $\left(\mathrm{cm}^{3}\right)$ & 25,176 & 26,129 & 311,824 \\
\hline Volume da resina $\left(\mathrm{cm}^{3}\right)$ & 279,684 & 267,582 & 337,190 \\
\hline Volume do compósito $\left(\mathrm{cm}^{3}\right)$ & 304,860 & 293,711 & 7,523 \\
\hline Fração volumétrica de fibra (\%) & 8,258 & 8,896 & 92,477 \\
\hline Fração volumétrica da resina (\%) & 91,742 & 91,104 & \\
\hline
\end{tabular}

Os valores médios das densidades medidas das fibras, das resinas e dos compósitos e os respectivos desvios-padrão são apresentados na Tabela 2.

Tabela 2: Densidade das fibras, das resinas e dos compósitos.

\begin{tabular}{|c|c|c|}
\hline MATERIAL & DENSIDADE MÉDIA (g/cm³) & DESVIO PADRÃO $\left(\mathrm{g} / \mathrm{cm}^{3}\right)$ \\
\hline Fibra & 0,38 & 0,03 \\
\hline Resina de poliéster isoftálico & 1,17 & 0,05 \\
\hline Resina de poliéster ortoftálico & 1,20 & 0,05 \\
\hline Resina de epóxi & 1,13 & 0,02 \\
\hline Compósito - matriz de poliéster isoftálico & 1,10 & 0,07 \\
\hline Compósito - matriz de poliéster ortoftálico & 1,16 & 0,09 \\
\hline Compósito - matriz de epóxi & 1,05 & 0,11 \\
\hline
\end{tabular}

\subsection{Caracterização mecânica das fibras - Ensaio de Tração}

A Tabela 3 apresenta os valores dos diâmetros médios medidos ao longo das trinta amostras da fibra testadas, e os respectivos valores das propriedades mecânicas obtidas a partir dos ensaios de tração realizados nestas amostras.

Tabela 3: Resultados dos ensaios de tração das fibras da folha de buriti.

\begin{tabular}{c|c|c|c|c|c|c}
\hline PARÂMETRO & $\begin{array}{c}\text { DIÂMETRO } \\
\text { MÉDIO (MM) }\end{array}$ & $\begin{array}{c}\text { FORÇA } \\
\text { MÁXIMA } \\
\mathbf{( N )}\end{array}$ & $\begin{array}{c}\text { TENSÃO DE } \\
\text { ESCOAMENTO } \\
\text { (MPa) }\end{array}$ & $\begin{array}{c}\text { TENSÃO } \\
\text { MÁXIMA } \\
(\mathbf{M P a})\end{array}$ & $\begin{array}{c}\text { MÓDULO DE } \\
\text { ELASTICIDADE } \\
\text { (GPa) }\end{array}$ & $\begin{array}{c}\text { ALONGAMENTO } \\
\text { NA RUPTURA } \\
\text { (\%) }\end{array}$ \\
\hline Média & 0,53 & 36,7 & 87,3 & 148,1 & 5,8 & 3,5 \\
\hline Desvio Padrão & 0,24 & 27,1 & 26,0 & 35,8 & 2,0 & 1,5 \\
\hline Mínimo & 0,15 & 3,0 & 51,9 & 100,8 & 3,2 & 1,4 \\
\hline Máximo & 0,96 & 96,0 & 165,6 & 224,1 & 11,6 & 6,9 \\
\hline
\end{tabular}

A Figura 6 mostra o comportamento da resistência máxima das fibras em função de seu diâmetro. 


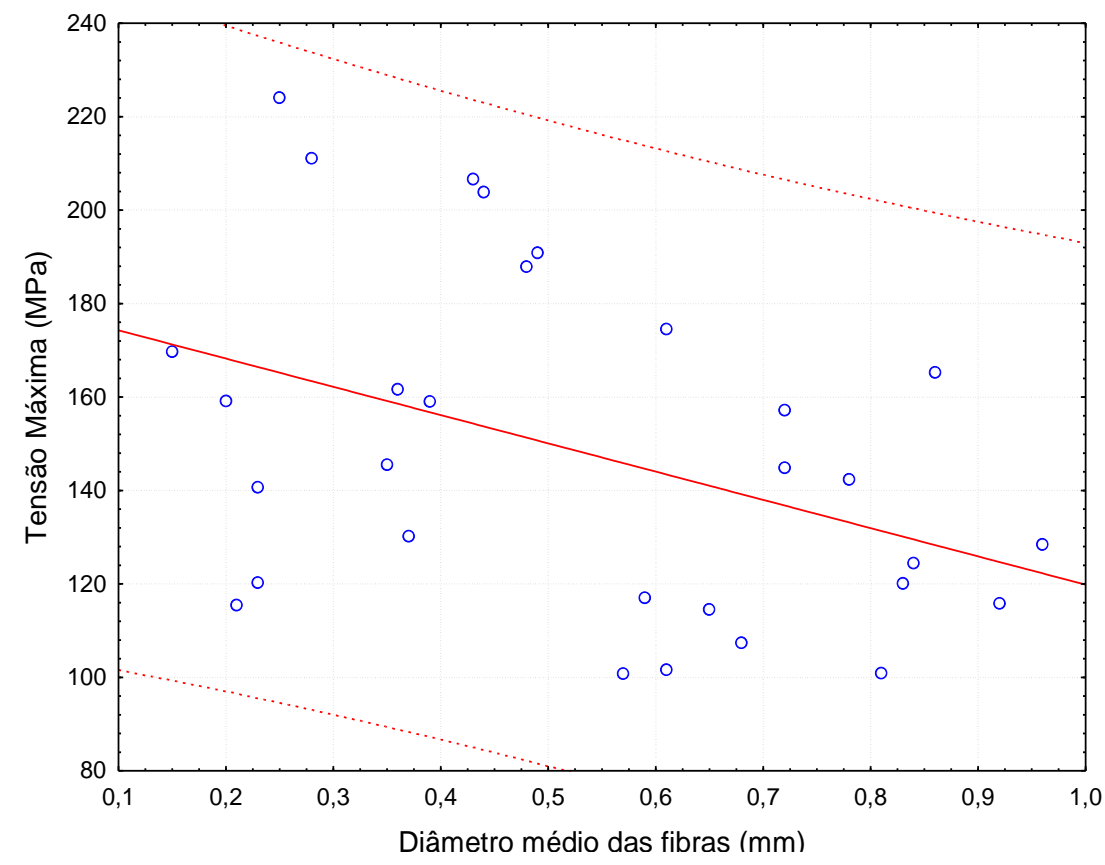

Figura 6: Curva de variação da tensão máxima à tração da fibra da folha de buriti em função do diâmetro.

Verificou-se na Figura 6 uma tendência de queda da resistência máxima à tração em função do diâmetro das fibras, embora seja possível observar uma grande dispersão dos pontos.

A Figura 7 apresenta um diagrama típico de tensão x deformação das fibras da folha do buriti analisadas.

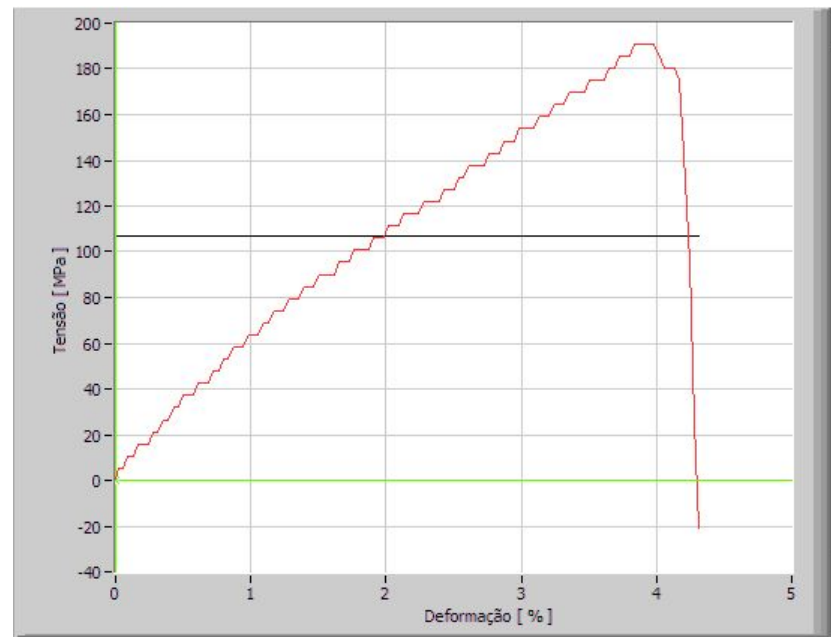

Figura 7: Curva tensão x deformação típica da fibra da folha do buriti.

Pode-se observar na Figura 7, serrilhados na curva tensão x deformação devido a pequenas deformações na fibra em carga constante, durante todo o ensaio. Observou-se também durante os ensaios, que essas deformações apresentadas no gráfico não ocorreram por escorregamento das fibras na garra da máquina de ensaio, pois foram feitas marcas nas fibras próximas às garras e essas marcas permaneceram à mesma distância das garras durante todo o ensaio, até a ruptura das fibras.

A Figura 8 mostra a imagem de MEV do aspecto da fratura da fibra submetida ao ensaio de tração. 


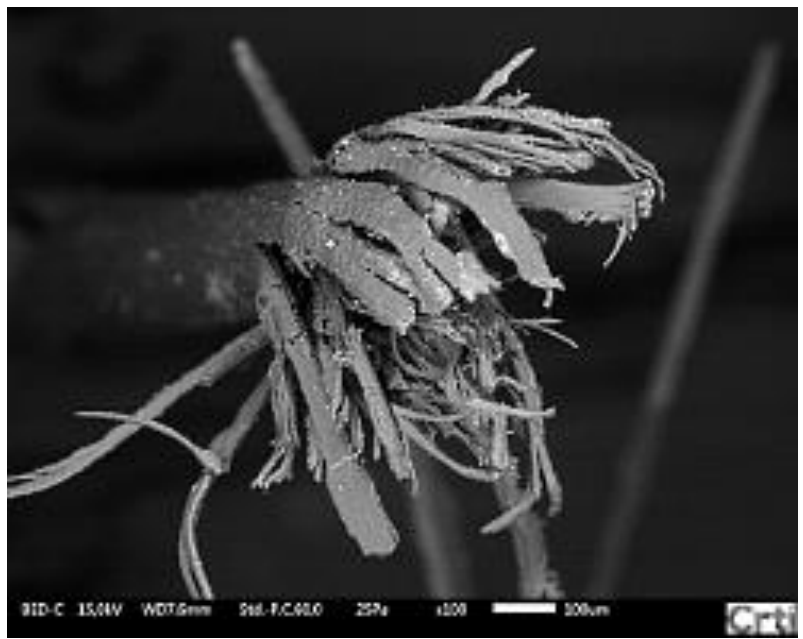

Figura 8: Aspecto da fratura da fibra no ensaio de tração (100x).

Observa-se na Figura 8 que a fibra rompe catastroficamente, estilhaçando-se na ruptura. Verificou-se também uma ruptura longitudinal ao longo de cada furo observado nas figuras $1 \mathrm{~b}$ e $2 \mathrm{~b}$, nas linhas longitudinais observadas nas figuras $1 \mathrm{a}, 2 \mathrm{a}$ e $2 \mathrm{~b}$. Aparentemente a ruptura ocorre nas paredes mais finas que circundam o lúmen da fibra.

\subsection{Ensaio de arrancamento (pullout test)}

As tabelas 4, 5 e 6 apresentam os resultados dos ensaios de arrancamento entre a fibra da folha de buriti e as resinas de poliéster isoftálico, poliéster ortoftálico e epóxi, respectivamente. São apresentados os valores médios dos diâmetros das fibras e da tensão de tração de quatro réplicas para cada comprimento embutido com seus respectivos desvios-padrão (DP).

Tabela 4: Resultados dos ensaios de arrancamento das fibras de buriti da matriz de poliéster isoftálico.

\begin{tabular}{c|c|c|c}
\hline $\begin{array}{c}\text { COMPRIMENTO } \\
\text { EMBUTIDO } \\
\text { (MM) }\end{array}$ & $\begin{array}{c}\text { DIÂMETRO MÉDIO } \\
\text { (DP) } \\
\text { (MM) }\end{array}$ & $\begin{array}{c}\text { TENSÃO DE TRAÇÃO } \\
\text { (DP) } \\
(\mathbf{M P a})\end{array}$ & RESULTADO \\
\hline 2 & $0,30(0,03)$ & $77,0(48,6)$ & Escorregamento em todos os Corpos de Prova \\
\hline 3 & $0,17(0,04)$ & $203,1(62,4)$ & Ruptura em todos os Corpos de Prova \\
\hline 5 & $0,24(0,08)$ & $153,7(7,3)$ & Ruptura em todos os Corpos de Prova \\
\hline 10 & $0,25(0,09)$ & $195,2(32,0)$ & Ruptura em todos os Corpos de Prova \\
\hline
\end{tabular}

Tabela 5: Resultados dos ensaios de arrancamento das fibras de buriti da matriz de poliéster ortoftálico.

\begin{tabular}{c|c|c|c}
\hline $\begin{array}{c}\text { COMPRIMENTO } \\
\text { EMBUTIDO } \\
\text { (MM) }\end{array}$ & $\begin{array}{c}\text { DIÂMETRO MÉ- } \\
\text { DIO (DP) } \\
\text { (MM) }\end{array}$ & $\begin{array}{c}\text { TENSÃO DE } \\
\text { TRAÇÃO (DP) } \\
\text { (MPa) }\end{array}$ & RESULTADO \\
\hline 5 & $0,67(0,12)$ & $18,0(13,0)$ & Escorregamento em todos os Corpos de Prova \\
\hline 10 & $0,59(0,09)$ & $75,1(28,8)$ & Escorregamento e ruptura em metade dos corpos de prova cada \\
\hline 20 & $0,63(0,13)$ & $33,7(15,1)$ & Escorregamento e ruptura em metade dos corpos de prova cada \\
\hline 30 & $0,66(0,11)$ & $63,7(29,8)$ & Ruptura em todos os Corpos de Prova \\
\hline 40 & $0,63(0,10)$ & $95,7(37,2)$ & Ruptura em todos os Corpos de Prova \\
\hline
\end{tabular}


Tabela 6: Resultados dos ensaios de arrancamento das fibras de buriti da matriz de epóxi.

\begin{tabular}{c|c|c|c}
\hline $\begin{array}{c}\text { COMPRIMENTO EM- } \\
\text { BUTIDO } \\
\text { (MM) }\end{array}$ & $\begin{array}{c}\text { DIÂMETRO MÉDIO } \\
\text { (DP) } \\
\text { (MM) }\end{array}$ & $\begin{array}{c}\text { TENSÃO DE TRAÇÃO } \\
\text { (DP) } \\
\text { (MPa) }\end{array}$ & RESULTADO \\
\hline 1 & $0,37(0,07)$ & $57,0(24,9)$ & Ruptura em todos os Corpos de Prova \\
\hline 2 & $0,32(0,11)$ & $85,7(53,2)$ & Ruptura em todos os Corpos de Prova \\
\hline 3 & $0,34(0,05)$ & $103,9(39,7)$ & Ruptura em todos os Corpos de Prova \\
\hline 5 & $0,34(0,07)$ & $61,6(39,7)$ & Ruptura em todos os Corpos de Prova \\
\hline
\end{tabular}

Para a determinação do comprimento crítico de embutimento, foram feitos gráficos, seguindo a metodologia apresentada MONTEIRO e D’ALMEIDA [16]. A Figura 9 apresenta o gráfico usado para a determinação do comprimento crítico quando se utilizou a resina de poliéster isoftálico.

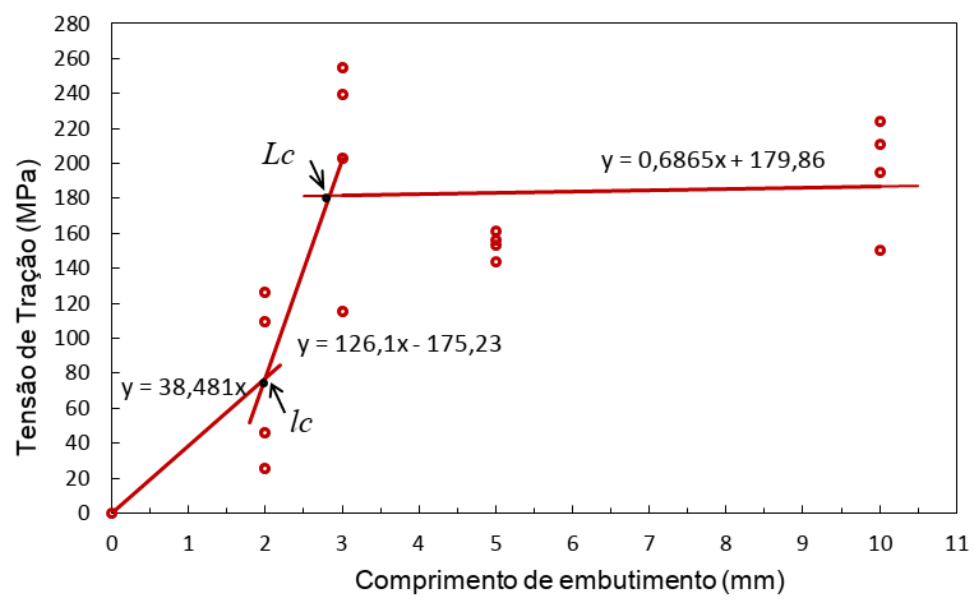

Figura 9: Comprimento embutido x tensão de tração e para curvas de pullout em fibras de buriti embutidas em matriz de poliéster isoftálico.

A Figura 10 apresenta o gráfico utilizado para a determinação do comprimento crítico, a partir da intersecção das curvas, para o caso da resina de poliéster ortoftálico.

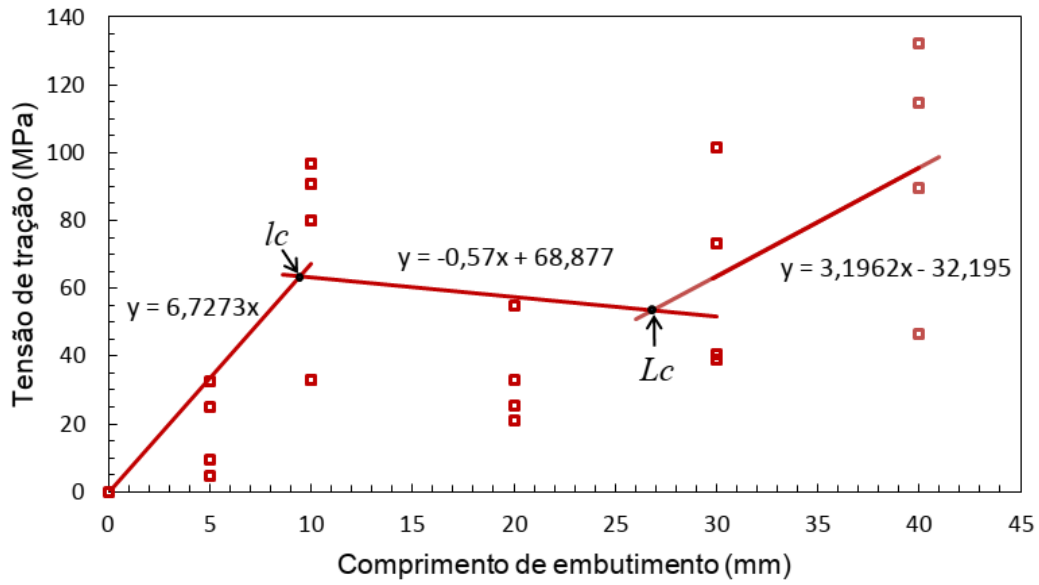

Figura 10: Comprimento embutido x tensão de tração e para curvas de pullout em fibras de buriti em matriz de poliéster ortoftálico.

Para a determinação do comprimento crítico $l c$ a partir das figuras 7 e 8, utilizou-se a metodologia com três curvas, sendo a primeira começando da origem, seguindo até encontrar os pontos onde começou a haver desacoplamento (debonding) da fibra em relação à matriz, a segunda curva começa no ponto onde termina a primeira e vai até o ponto onde não há mais desacoplamento da fibra em relação à matriz, e a terceira vai do 
final da segunda curva até o comprimento máximo de embutimento testado, representando o intervalo onde não há mais desacoplamento da fibra em relação à matriz. Neste caso, existem dois comprimentos críticos, sendo $l c$, que é o comprimento crítico para livre desacoplamento da fibra, determinado pela intersecção das duas primeiras curvas (a partir da origem), e $L c$, que é comprimento a partir do qual não ocorre mais desacoplamento da fibra em relação à matriz, determinado pela intersecção da curva intermediária e a curva mais à direita no gráfico. Esta metodologia foi proposta originalmente por KELLY e TYSON [21] e adaptada por MONTEIRO e D’ALMEIDA [16].

Calculando-se a intersecção entre as duas primeiras curvas da Figura 9, determinou-se o valor de $l c=$ 2,0 mm e da intersecção entre as duas últimas curvas, determinou-se $L c=2,8 \mathrm{~mm}$. Para o caso da Figura 10, determinou-se o valor de $l c=9,4 \mathrm{~mm}$ e $L c=26,8 \mathrm{~mm}$. Como $L c$ representa o comprimento a partir do qual não ocorre mais desacoplamento da fibra em relação à matriz, é mais apropriado seu uso para o cálculo da tensão cisalhante interfacial [16].

No caso da matriz de epóxi, como não foi possível fazer embutimentos menores que 1,0 mm de profundidade, e para esse valor houve ruptura sem desacoplamento das fibras em todos os testes, admitiu-se, para efeito de cálculo da tensão cisalhante interfacial, o comprimento embutido de $1,0 \mathrm{~mm}$ como o comprimento crítico.

Para os cálculos da tensão cisalhante interfacial $\left(\tau_{c}\right)$ entre a fibra da folha de buriti e as resinas testadas (poliéster isoftálico e ortoftálico e epóxi), utilizou-se o limite de resistência à tração médio das fibras da folha de buriti de 148,1 MPa e seu raio médio de 0,27 mm e a Equação (1).

Para o compósito com resina de poliéster isoftálico, usando o comprimento crítico $L c=2,8 \mathrm{~mm}$, calculou-se a tensão cisalhante interfacial $\tau_{c}=7,1 \mathrm{MPa}$. Para o compósito com resina de poliéster ortoftálico, calculou-se a tensão cisalhante interfacial a partir de $L c=26,8 \mathrm{~mm}$, obtendo-se $\tau_{c}=0,8 \mathrm{MPa}$. Para o compósito com resina epóxi, admitindo-se o comprimento crítico de $1,0 \mathrm{~mm}$, determinou-se a tensão cisalhante interfacial $\tau_{c}=20,0 \mathrm{MPa}$.

A partir dos cálculos da tensão cisalhante interfacial, observou-se que a adesão entre a fibra da folha de buriti e o epóxi foi a maior entre os pares fibra/matriz testados, seguido pelo par fibra de buriti/poliéster isoftálico e, por último, o par fibra de buriti/poliéster ortoftálico, que apresentou uma tensão cisalhante interfacial menor que os dois primeiros.

Observou-se durante os ensaios de arrancamento que, mesmo em alguns testes onde houve ruptura da fibra sem um escorregamento aparente desta, as curvas tensão x deformação se comportaram de forma distinta daquela observada nos ensaios somente da fibra, como observado na Figura 7. A Figura 11 mostra curvas típicas dos ensaios de arrancamento.

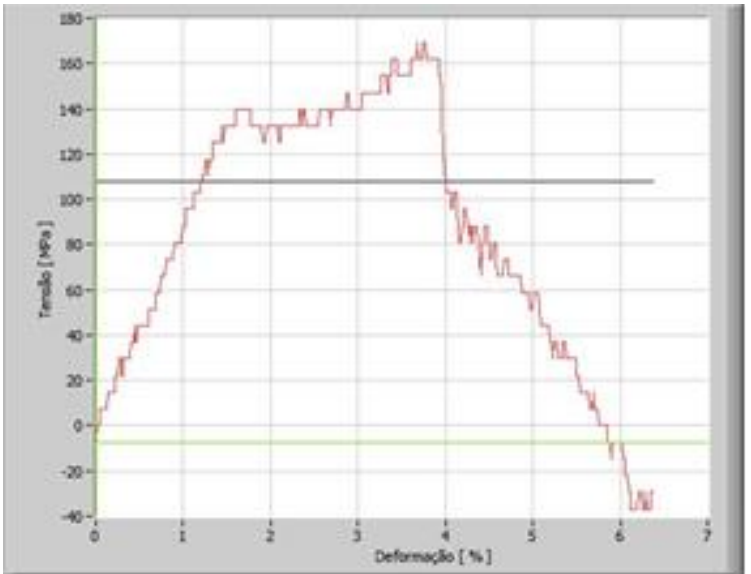

(a)

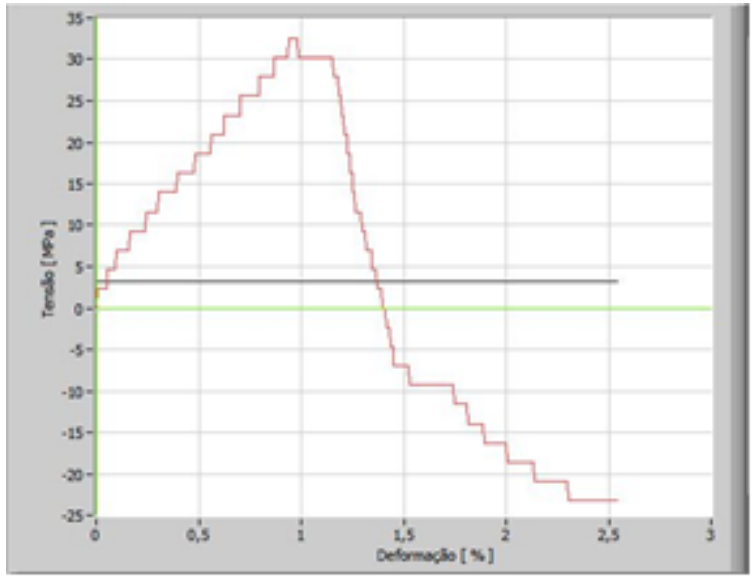

(b) 


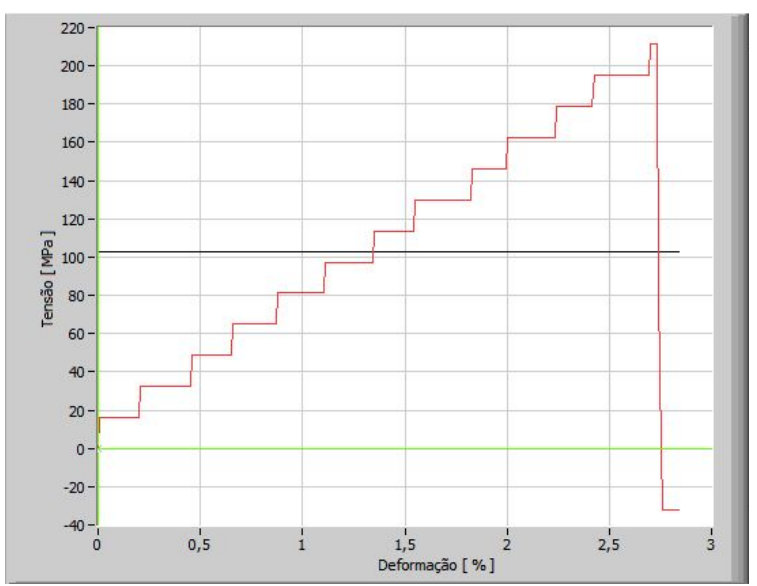

Figura 11: Curvas tensão $x$ deformação típicas dos ensaios de arrancamento onde ocorreu: (a) escorregamento completo da fibra; (b) escorregamento parcial da fibra com ruptura da fibra fora da capsula polimérica; (c) ruptura da fibra fora da capsula polimérica.

A Figura 11 mostra duas características observadas nos testes de arrancamento: a primeira é que nos ensaios onde houve escorregamento da fibra (Figura 11a), a tensão máxima normalmente é sempre menor que a resistência à tração média determinada para a fibra estudada; a segunda é que, em alguns ensaios, mesmo quando houve ruptura da fibra fora da capsula polimérica (Figura 11b), existe uma região na parte superior da curva onde a tensão não acompanhou a deformação, provavelmente devido a um escorregamento parcial da fibra, diferente do que foi observado na Figura 7 nos ensaios de determinação da resistência da fibra. Nos ensaios onde houve ruptura da fibra fora da capsula polimérica, sem sinais de escorregamento (Figura 11c), o comportamento da curva foi semelhante àquele observado nos ensaios de resistência da fibra.

Observou-se também, através de imagens de MEV, o aspecto da fibra após o ensaio de arrancamento (Figura 12). O comportamento foi semelhante para os três tipos de resina usados nesta pesquisa.
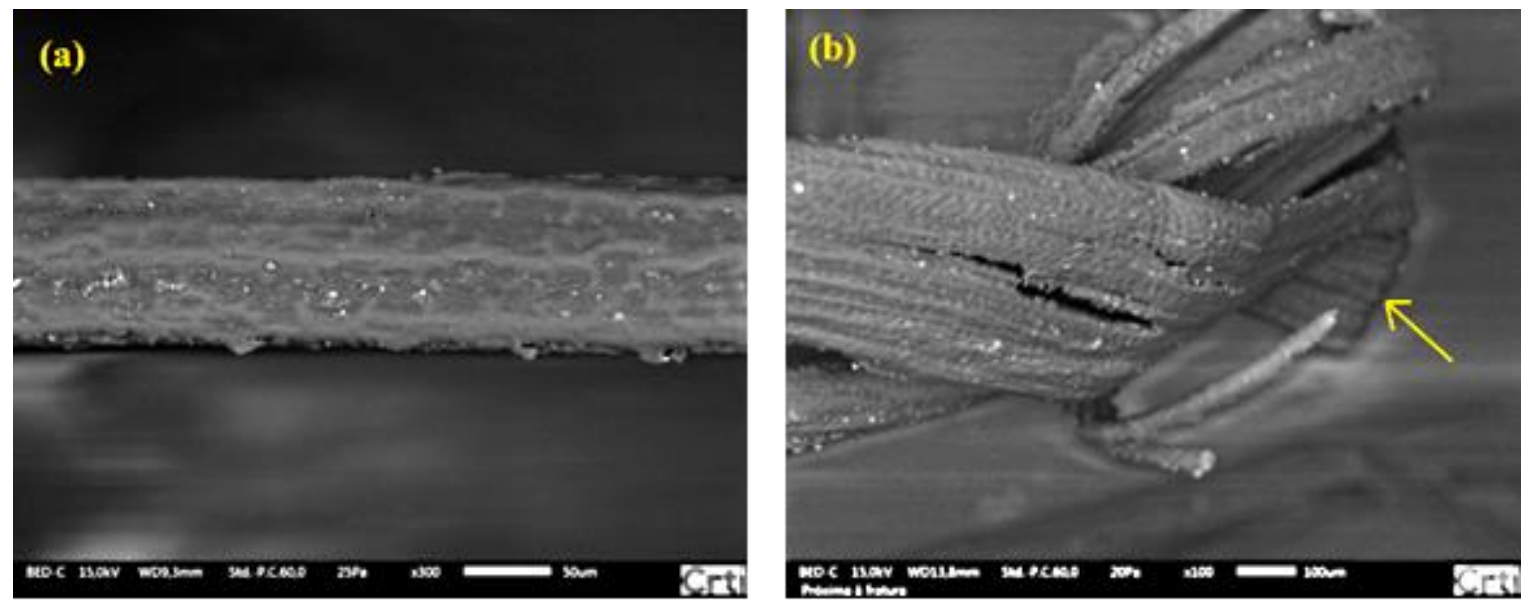

Figura 12: Aspecto das fibras após ensaio de arrancamento. (a) Ensaio com escorregamento da fibra (300x); (b) ensaio com fratura da fibra (100x).

Na Figura 12a é possível observar parte da resina que ficou aderida na fibra (partes brilhantes mais claras) nos ensaios onde houve escorregamento da fibra de dentro da matriz polimérica. Isto mostra que houve alguma adesão, mas que não foi suficiente para evitar o desacoplamento da fibra de dentro da matriz.

Na Figura 12b a seta indica a área de ligação entre a matriz e a fibra. Pode-se observar que não há sinais de desacoplamento da fibra e seu estilhaçamento após a ruptura é semelhante àquele observado na Figura 8.

\subsection{Caracterização mecânica das resinas - Ensaio de Tração}


A Tabela 7 apresenta os valores médios e o desvio padrão das propriedades mecânicas obtidas nos ensaios de tração das resinas. A resistência das resinas foi determinada para que se tenha uma referência das resistências dos compósitos criados, ou seja, o quanto a fibra contribuiu na resistência final do respectivo compósito.

Tabela 7: Propriedades em tração das resinas.

\begin{tabular}{c|c|c|c|c|c}
\hline RESINA & $\begin{array}{c}\text { FORÇA MÁXI- } \\
\text { MA (DP) } \\
\text { (KN) }\end{array}$ & $\begin{array}{c}\text { TENSÃO DE ES- } \\
\text { COAMENTO (DP) } \\
\text { (MPA) }\end{array}$ & $\begin{array}{c}\text { TENSÃO MÁXI- } \\
\text { MA (DP) } \\
\text { (MPA) }\end{array}$ & $\begin{array}{c}\text { MÓDULO ELÁSTI- } \\
\text { CO (DP) } \\
\text { (GPA) }\end{array}$ & $\begin{array}{c}\text { ALONGAMENTO NA } \\
\text { RUPTURA (DP) } \\
\text { (\%) }\end{array}$ \\
\hline Poliéster Isoftálico & $3,0(1,0)$ & $30,3(14,5)$ & $34,5(12,3)$ & $2,1(0,8)$ & $2,5(0,9)$ \\
\hline Poliéster Ortoftálico & $2,6(0,4)$ & $16,7(3,0)$ & $27,7(2,9)$ & $1,5(0,3)$ & $3,4(0,3)$ \\
\hline Epóxi & $2,7(0,3)$ & $13,7(0,7)$ & $60,5(2,0)$ & $2,2(0,4)$ & $6,6(1,1)$ \\
\hline
\end{tabular}

Na Figura 13 são apresentas curvas de tensão x deformação típicas das três matrizes poliméricas analisadas.

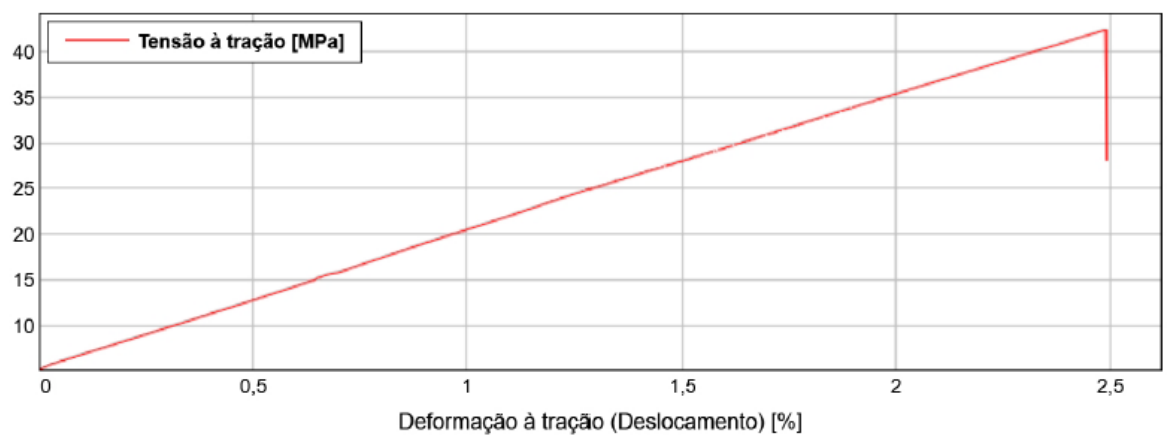

(a) Poliéster isoftálico

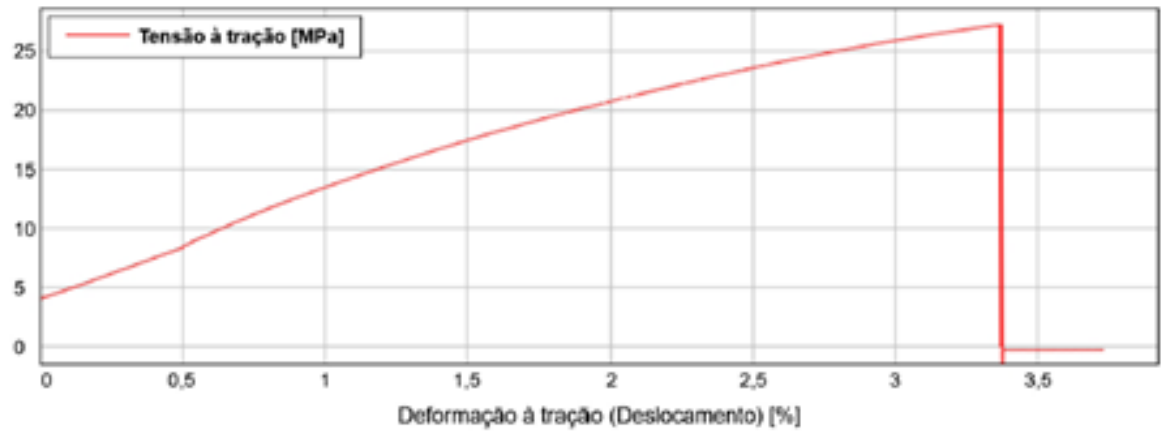

(b) Poliéster ortoftálico

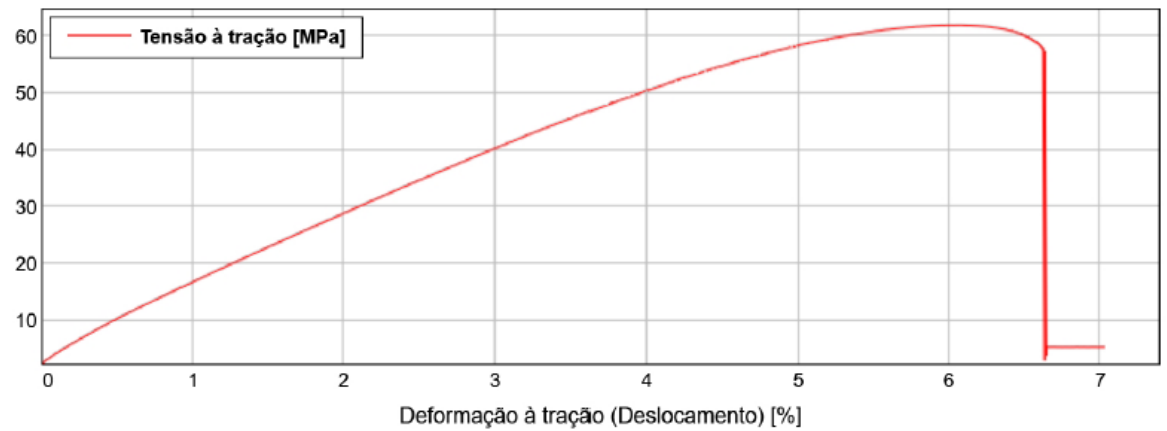

(c) Epóxi

Figura 13: Curvas tensão $x$ deformação típicas das matrizes poliméricas.

\subsection{Caracterização mecânica dos compósitos - Ensaio de Tração}


Nesta etapa, foram feitos os ensaios de tração nos corpos de prova dos compósitos confeccionados a partir da fibra da folha de buriti nas matrizes poliméricas de poliéster isoftálico e ortoftálico e de epóxi, conforme apresentado na Tabela 8.

Tabela 8: Propriedades em tração dos compósitos da fibra da folha de buriti em matriz polimérica.

\begin{tabular}{c|c|c|c|c|c}
\hline MATRIZ & $\begin{array}{c}\text { FORÇA } \\
\text { MÁXIMA (DP) } \\
\text { (KN) }\end{array}$ & $\begin{array}{c}\text { TENSÃO DE } \\
\text { ESCOAMENTO (DP) } \\
\text { (MPA) }\end{array}$ & $\begin{array}{c}\text { TENSÃO } \\
\text { MÁXIMA (DP) } \\
\text { (MPA) }\end{array}$ & $\begin{array}{c}\text { MÓDULO DE } \\
\text { ELASTICIDADE (DP) } \\
\text { (GPA) }\end{array}$ & $\begin{array}{c}\text { ALONGAMENTO } \\
\text { NA RUPTURA (DP) } \\
\text { (\%) }\end{array}$ \\
\hline $\begin{array}{c}\text { Poliéster } \\
\text { Isoftálico }\end{array}$ & $3,4(0,2)$ & $26,4(3,2)$ & $29,1(2,9)$ & $1,1(0,1)$ & $4,1(0,3)$ \\
\hline $\begin{array}{c}\text { Poliéster } \\
\text { Ortoftálico }\end{array}$ & $2,0(0,4)$ & $11,6(5,7)$ & $16,1(2,9)$ & $1,3(0,2)$ & $1,8(0,3)$ \\
\hline Epóxi & $4,3(0,5)$ & $24,5(23,5)$ & $46,8(6,3)$ & $1,2(0,5)$ & $6,5(1,0)$ \\
\hline
\end{tabular}

A Tabela 8 mostra uma diferença entre as resistências médias à tração dos compósitos confeccionados com as três resinas estudadas neste trabalho, porém, para verificar se essa diferença é significativa, foi feita uma análise de variância com um nível de significância de 5\%, para verificar se o tipo de resina influenciou na resistência à tração do compósito criado com a fibra da folha de buriti. A Tabela 9 apresenta esta análise de variância.

Tabela 9: Análise de variância para testar a influência do tipo de resina na resistência à tração do compósito.

\begin{tabular}{c|c|c|c|c|c|c}
\hline FONTE DA VARIAÇÃO & SQ & GL & MQ & F & VALOR-P & F CRÍTICO \\
\hline Entre grupos & 3045,27 & 2 & 1522,63 & 25,39 & 0,000049 & 3,88 \\
\hline Dentro dos grupos & 719,71 & 12 & 59,98 & & & \\
\hline Total & 3764,97 & 14 & & & & \\
\hline
\end{tabular}

A Tabela 9 mostra que o tipo de resina influenciou significativamente na resistência dos compósitos criados, como pode ser comprovado tanto pelo valor de $\mathrm{F}$ ter ficado maior que o valor de $\mathrm{F}$ crítico, quanto pelo valor-p ter sido menor que o valor do nível de significância fixado de 5\% $(0,05)$.

Na Figura 14 são apresentas curvas de tensão x deformação típicas dos compósitos criados a partir das fibras das folhas de buriti nas três matrizes poliméricas analisadas.

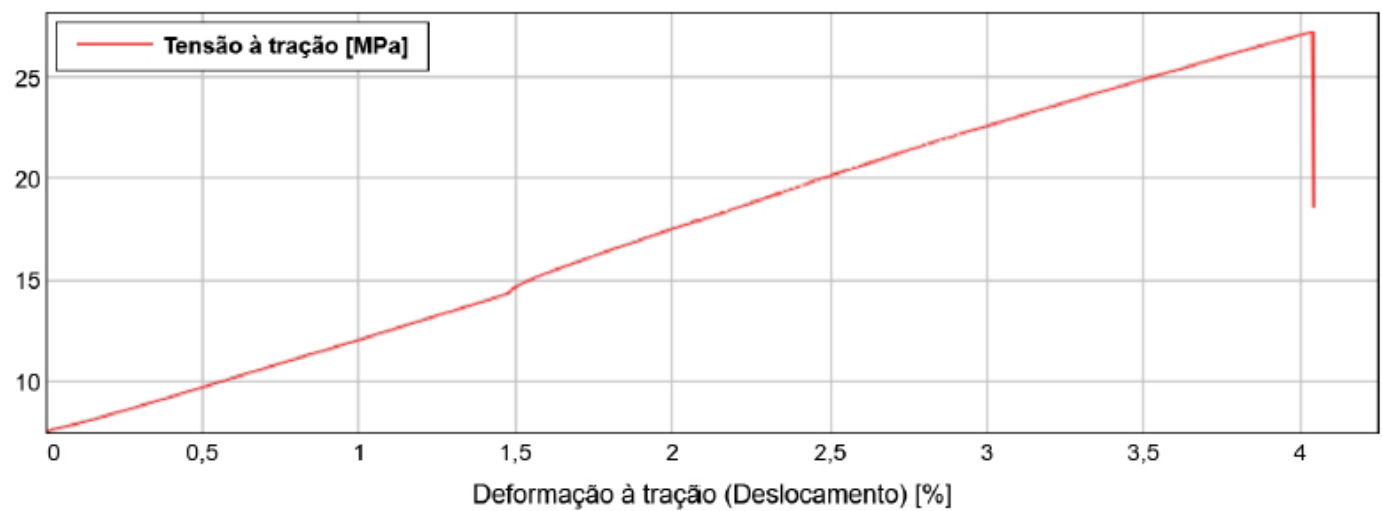

(a) Compósito com matriz de poliéster isoftálico 


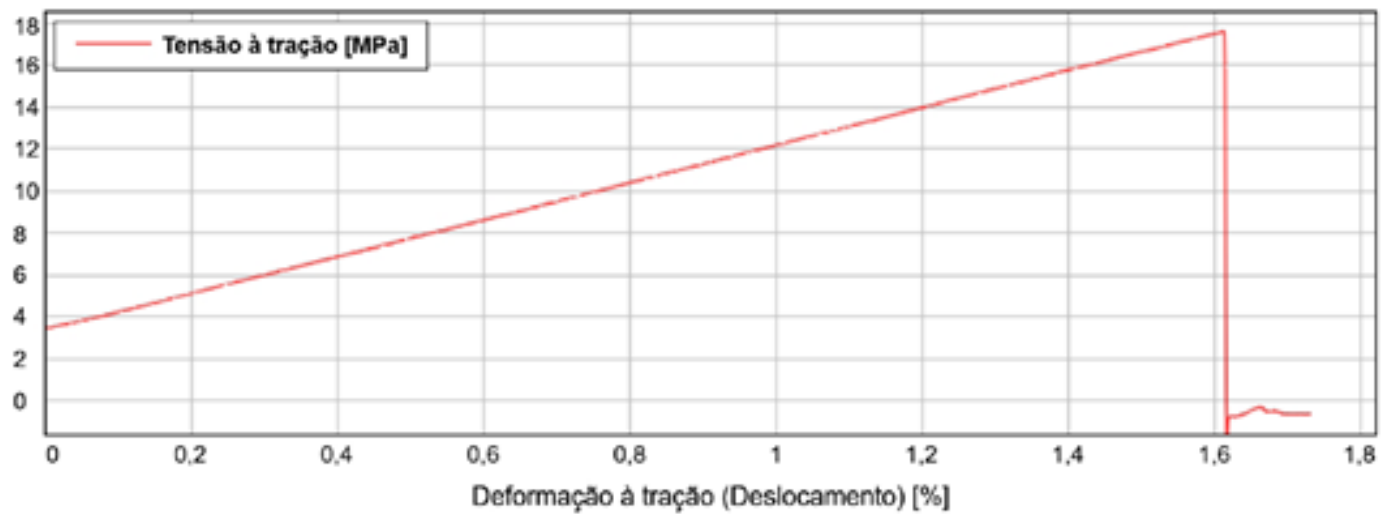

(b) Compósito com matriz de poliéster ortoftálico

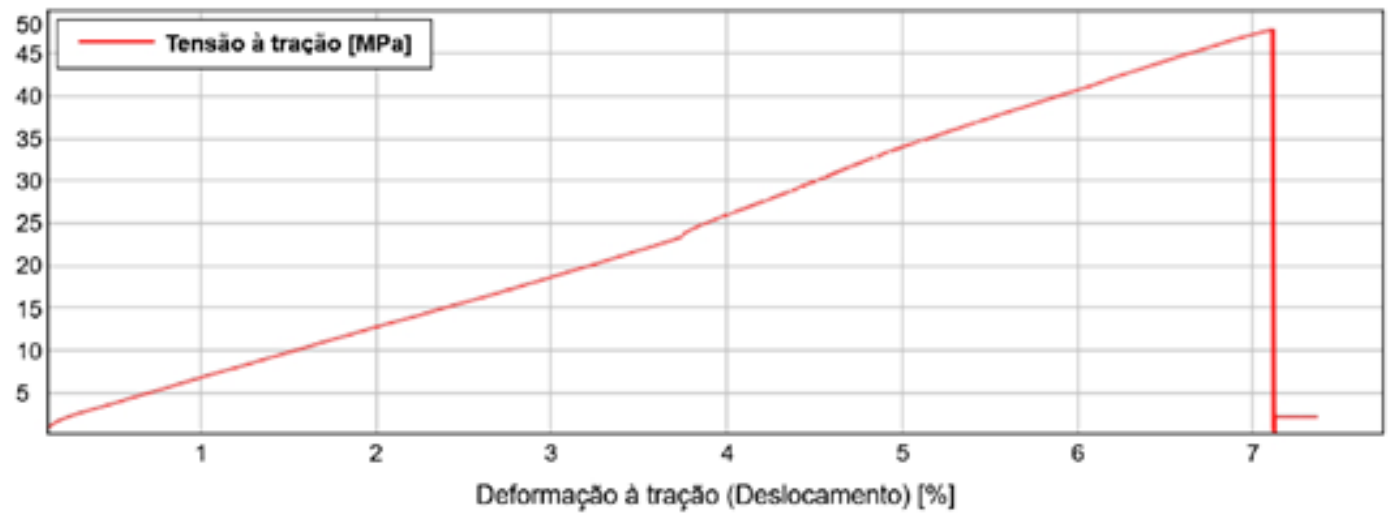

(c) Compósito com matriz de epóxi

Figura 14: Curvas tensão $x$ deformação típicas dos compósitos criados com as fibras da folha de buriti nas três matrizes poliméricas.

Outro comportamento observado nos ensaios de tração nos compósitos foi que em alguns testes com as matrizes de poliéster, tanto isoftálico quanto ortoftálico, houve ruptura da matriz sem que as fibras se rompessem completamente, conforme pode ser observado na Figura 15.

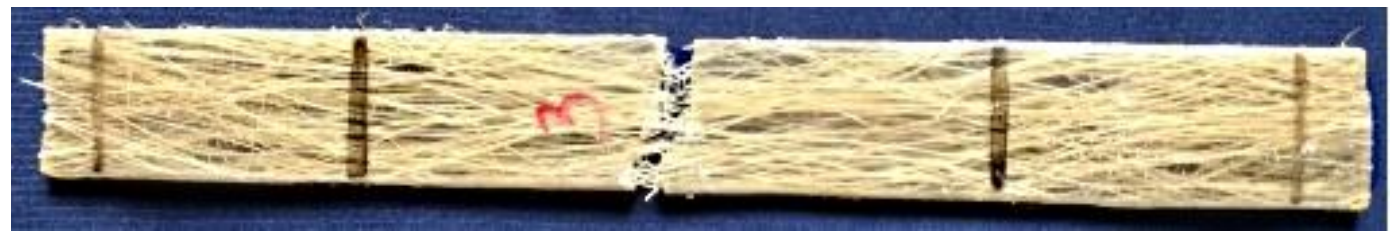

Figura 15: Corpo de prova com ruptura parcial das fibras e total da matriz de poliéster ortoftálico.

A Figura 16a apresenta a imagem de MEV mostrando o comportamento de ruptura apresentado na Figura 15. 

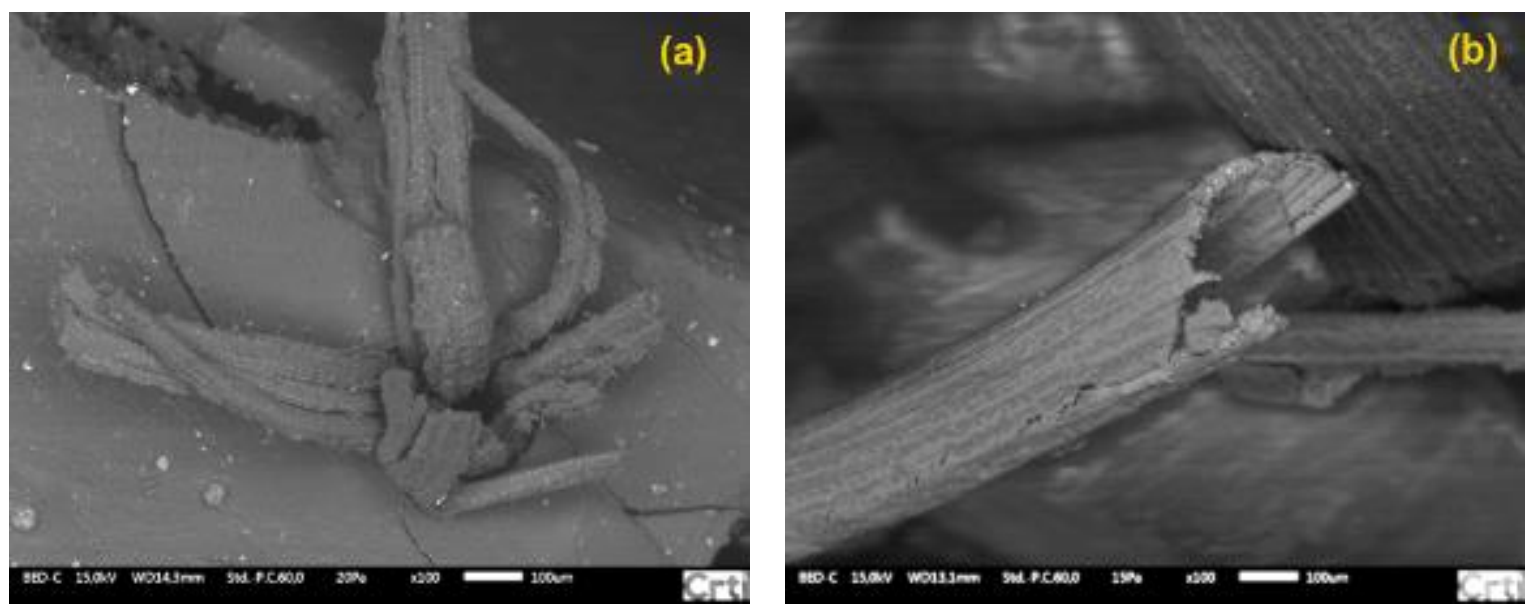

Figura 16: Ruptura do compósito com matriz ortoftálico. (a) Aspecto do desacoplamento da fibra de dentro da matriz (100x); (b) falha da fibra na seção longitudinal (100x).

Observa-se na Figura 16a o aspecto do desacoplamento da fibra de dentro da matriz do corpo de prova apresentado na Figura 15. A Figura 16b mostra que a fibra falhou ao longo de seu comprimento, comprometendo a adesão da fibra na matriz e, consequentemente, a resistência do compósito.

\section{DISCUSSÃO}

\subsection{Caracterização dos materiais utilizados}

Com relação à estrutura da fibra mostrada na Figura 1b e nas figuras 2a e 2b, PASSOS e MENDONÇA [20] verificaram, através de análise em imagens feitas em MEV, que tanto na região adaxial como na epiderme da face abaxial das folhas do buriti, as células epidérmicas apresentam-se com paredes retas, espessas e orientadas no sentido longitudinal do segmento foliar, favorecendo a resistência à tração nesta direção. Observou-se nas figuras $2 \mathrm{a}$ e $2 \mathrm{~b}$ nervuras na superfície das fibras comprovando as observações dos autores citados acima.

As medidas de densidade das fibras apresentaram um valor médio de $0,38 \mathrm{~g} / \mathrm{cm}^{3}$, valor menor que de outras fibras lignocelulósicas estudadas em outras pesquisas como, por exemplo, a fibra do pecíolo da folha do buriti, com densidade variando entre $0,63-1,12 \mathrm{~g} / \mathrm{cm}^{3}$ [6], o sisal com densidade entre 1,3 e $1,5 \mathrm{~g} / \mathrm{cm}^{3}, \mathrm{o}$ coco com 1,2 g/cm ${ }^{3}$ [9] e o bambu com $1,03-1,21 \mathrm{~g} / \mathrm{cm}^{3}$ [2]. Quando comparado com as principais fibras sintéticas comerciais, como a fibra de carbono com densidade de $1,78-1,81 \mathrm{~g} / \mathrm{cm}^{3}$ e a de vidro com $2,50-$ $2,58 \mathrm{~g} / \mathrm{cm}^{3}$ [2], a diferença de densidade fica ainda mais evidente, mostrando que a fibra da folha do buriti pode produzir compósitos mais leves que aqueles produzidos pelas fibras estudadas e usada atualmente.

\subsection{Caracterização mecânica das fibras - Ensaio de Tração}

Os resultados apresentados na Tabela 3 mostraram que houve uma grande dispersão dos valores de resistência à tração. Segundo LAU et al. [22], as fibras naturais são geralmente irregulares e variam em diâmetro ao longo de sua direção longitudinal, desta forma, sua medição pode levar a erros na determinação da tensão, além da própria estrutura que varia de uma fibra para outra, devido à heterogeneidade das fibras lignocelulósicas. As propriedades de fibras da mesma espécie podem variar consideravelmente, dependendo da origem da fibra (fruta, pecíolos, folhas etc.), do local de onde a planta foi extraída, da idade da planta e do précondicionamento das fibras [23]. As condições ambientais como radiação solar e a disponibilidade de água influenciam o crescimento e o desenvolvimento dos tecidos vegetais [20]. Como as fibras usadas neste estudo não foram retiradas todas da mesma folha, ou da mesma planta, é provável que esse fato, e a imprecisão inerente da determinação do diâmetro da fibra, podem ser alguns dos motivos da dispersão dos valores obtidos de resistência à tração nos ensaios.

Apesar da dispersão dos valores obtidos de resistência à tração, os níveis médios estão próximos aos de outras fibras usadas em compósitos de fibras lignocelulósicas, apresentados por MONTEIRO et al. [2] para as fibras do pecíolo da folha do buriti, com tensão máxima entre 129 e $254 \mathrm{MPa}$, para as fibras do bambu variando de 106 a $204 \mathrm{Mpa}$ e para as fibras da cana variando de 135 a $222 \mathrm{MPa}$. Entretanto, a fibra da folha 
do buriti possui densidade menor do que a das fibras citadas, proporcionando uma relação resistência/peso maior do que a de algumas delas. Para comparação, a fibra da folha de buriti apresentou uma relação máxima de tensão/densidade de $590 \mathrm{MPa} . \mathrm{cm}^{3} / \mathrm{g}$, enquanto que, de acordo com os dados apresentados por MONTEIRO et al. [2], a relação máxima foi de $403 \mathrm{MPa} \cdot \mathrm{cm}^{3} / \mathrm{g}$ para a fibra do pecíolo da folha de buriti, de 725 MPa.cm $3 / \mathrm{g}$ para fibra de sisal, de $191 \mathrm{MPa} . \mathrm{cm}^{3} / \mathrm{g}$ para a fibra de coco e de $198 \mathrm{MPa} . \mathrm{cm}^{3} / \mathrm{g}$ para a fibra de bambu, além das fibras sintéticas como a de vidro com $1380 \mathrm{MPa} . \mathrm{cm}^{3} / \mathrm{g}$ e a de carbono com $3567 \mathrm{MPa} . \mathrm{cm}^{3} / \mathrm{g}$.

As propriedades mecânicas das fibras naturais dependem do tipo e do teor de celulose e da geometria celular (orientação das microfibrilas), sendo que tanto o teor de celulose quanto as condições geométricas determinam as propriedades mecânicas [8, 22, 24]. DEMOSTHENES et al. [5] citam que o teor de celulose da fibra da folha de buriti é de aproximadamente 58\%, valor próximo a de outras fibras lignocelulósicas usadas na produção de compósitos de matriz polimérica como o pecíolo da folha do buriti (65-71\%), o Sisal (65$67 \%)$, a juta $(45-71 \%)$ e o rami $(68,6-91 \%)$ [25].

A tendência de queda da resistência à tração com o aumento do diâmetro da fibra (Figura 6) também foi observada por BARBOSA [6] em seu estudo com fibras do pecíolo da folha de buriti na faixa de diâmetros da fibra entre 0,1 e 0,8 mm. MONTEIRO et al. [2] mostraram esse comportamento para várias fibras lignocelulósicas estudadas como reforço em matriz polimérica, e afirmam que isso parece ser uma característica comum a todas as fibras desse tipo, devido a defeitos microestruturais e uma distribuição estatística intrínseca da resistência das microfibrilas de celulose. Este comportamento ocorre devido a defeitos associados a falhas apresentadas por causa da estrutura irregular ao longo das fibras. Assim, quanto maior a área superficial da fibra (diâmetros maiores), maior a probabilidade de falha devido a algum concentrador de tensão causado por uma irregularidade da estrutura da fibra [26]. As fibras naturais não são homogêneas ao longo de sua seção transversal, tornando-se cada vez mais porosa com o aumento do diâmetro. Esse fato pode proporcionar uma estrutura interna de fibra frouxa, aberta e fracamente cristalina, o que poderia ser uma das justificativas da redução da resistência da fibra com a elevação do seu diâmetro [27].

As fibras vegetais normalmente são compostas por um núcleo de lúmen que é envolvido por diferentes camadas da parede celular, com diferentes orientações de microfibrilas, que conferem força à fibra sujeita a diferentes cargas. Semelhante a outros sistemas de camada, o ângulo microfibrilar controla a resistência à tração das fibras naturais. Além disso, as microfibrilas não são idênticas, pois são compostas por regiões cristalinas e amorfas, nas quais a primeiro determina a força da fibra, enquanto a último é relativamente macia e formada por cadeias moleculares irregulares [22]. Assim, o comportamento de serrilhado nas curvas tensão $\mathrm{x}$ deformação, observado na Figura 7, pode ser devido a ou mais dos seguintes fatores: alinhamento e ruptura parcial das microfibrilas; desacoplamento entre as camadas que formam as fibras; alongamento da região cristalina das microfibrilas. A Figura 8 apresentou a fratura das fibras onde é possível ver que esta se separa em fibras mais finas. Assim, a ruptura individual e em tempos diferentes destas fibras, poderia ser outra explicação do serrilhado apresentado na Figura 7.

\subsection{Ensaio de arrancamento (pullout test)}

$\mathrm{Na}$ análise dos ensaios de arrancamento, a Tabela 4 mostrou que a transição entre escorregamento e ruptura da fibra na resina de poliéster isoftálico ocorreu entre os comprimentos de embutimento de 2 e $3 \mathrm{~mm}$, sendo o comprimento crítico $L c=2,8 \mathrm{~mm}$.

$\mathrm{Na}$ Tabela 5, observou-se que para a resina de poliéster ortoftálico, esta transição ocorreu entre 20 e 30 $\mathrm{mm}$, porém, neste caso, verificou-se que para os comprimentos de embutimento de $10 \mathrm{~mm}$ e $20 \mathrm{~mm}$, em metade dos testes ocorreu escorregamento da fibra e na outra metade houve ruptura. Para a resina de epóxi, verificou-se na Tabela 6 que não houve escorregamento em nenhum ensaio. Devido à alta maleabilidade da fibra, não foi possível fazer seu embutimento na resina para comprimentos menores que $1,0 \mathrm{~mm}$. Foram feitas tentativas com embutimento de $0,5 \mathrm{~mm}$, mas a fibra não se manteve na resina durante seu processo de endurecimento.

Observou-se nos testes de arrancamento que o diâmetro das fibras não influenciou nos resultados, pois para todos os pares fibra/matriz, o comportamento da tensão onde houve arrancamento ou ruptura em função do diâmetro da fibra foi aleatório, isto é, tanto para diâmetros maiores das fibras, quanto para os menores, a ruptura ou o escorregamento ocorreram em tensões de tração variadas, independente do diâmetro da fibra. Nestes ensaios, o diâmetro influenciou na tensão de ruptura da fibra, mas não influenciou no comportamento de adesão entre a fibra e a matriz. Este comportamento aleatório de resistência das fibras pode ser verificado pelo desvio padrão da tensão de tração observado nas tabelas 4,5 e 6 e na dispersão dos pontos das curvas das figuras 7 e 8. MARGEM et al. [28], realizando ensaios de arrancamento em fibras de malva embutidas em matriz de epóxi, verificaram desvios padrão semelhantes aos apresentados neste estudo. Verificou-se que 
essa grande dispersão é consequência das características heterogêneas intrínsecas apresentadas pelas fibras lignocelulósicas, à sua geometria irregular e à uniformidade do diâmetro [22, 29, 30].

Com respeito à determinação da tensão cisalhante interfacial, BARBOSA [6] apresentou resultados de compósitos de fibra do pecíolo da folha do buriti em matriz de epóxi, com $\tau_{c}=8,7 \mathrm{MPa}$. Quando se utiliza a Equação (1) do presente estudo, que considera o raio e não o diâmetro, a tensão cisalhante interfacial foi $\tau_{c}=$ 4,3 MPa, valor abaixo daquele encontrado nesta pesquisa, que utilizou o limbo da folha de buriti em matriz de epóxi, onde a tensão cisalhante interfacial calculada foi $\tau_{c}=20,0 \mathrm{MPa}$. Quando foi utilizada a resina de poliéster ortoftálico, BARBOSA [6] determinou $\tau_{c}=7,2 \mathrm{MPa}$, sendo $\tau_{c}=3,6 \mathrm{MPa}$ quando se considera o raio da fibra para o cálculo, contra $\tau_{c}=0,8 \mathrm{MPa}$ determinado no presente estudo. Comparando com os resultados obtidos na presente pesquisa, para a matriz de poliéster ortoftálico a tensão cisalhante interfacial obtida por BARBOSA [6] foi em torno de 4,5 vezes maior. Entretanto para a matriz de epóxi a tensão cisalhante interfacial obtida na atual pesquisa foi de aproximadamente 4,7 vezes maior que a obtida por BARBOSA [6]. Esses resultados mostraram que a ligação da interface fibra/matriz quando se utilizou a matriz de poliéster ortoftálico foi maior para a fibra do pecíolo de buriti do que para a fibra da folha (limbo) de buriti. No caso da matriz de epóxi os resultados se invertem, evidenciando que a ligação fibra/matriz é maior para a fibra da folha do que para a fibra do pecíolo de buriti.

Neste estudo, a interação fibra/matriz que apresentou uma tensão cisalhante interfacial maior foi para o sistema fibra de buriti/epóxi, com $\tau_{c}=20,0 \mathrm{MPa}$. Comparando este valor da tensão cisalhante interfacial com os de outros compósitos de fibras lignocelulósicas em matriz polimérica, o sistema fibra de malva/epóxi apresentou um valor de $\tau_{c}=3,1 \mathrm{MPa}$ [28], para o sistema fibra de coco/epóxi, $\tau_{c}=3,4 \mathrm{MPa}$ e para o sistema fibra de curauá/epóxi, $\tau_{c}=6,5 \mathrm{MPa}$ [16], além do sistema sisal/epóxi com $\tau_{c}=15,5 \mathrm{MPa}$ [31]. Estes resultados mostram que a fibra da folha de buriti é bastante promissora como reforço em compósitos de matriz polimérica, com relação à capacidade de adesão neste tipo de resina, principalmente em matriz de epóxi.

Com relação ao efeito do par fibra/matriz sobre a tensão cisalhante interfacial, de acordo com ZARGES et al. [13], a remoção da fibra da matriz circundante é realizada quando a carga necessária para o desacoplamento em estado estacionário é menor que a resistência máxima da fibra. Assim, para cada par fibra/matriz existe uma carga correspondente para que o desacoplamento da fibra ocorra. Esta ligação fibra/matriz depende de vários fatores físicos e químicos que é característico de cada par, incluindo a morfologia da interface, as características polares dos componentes, a energia da superfície e os fenômenos de molhabilidade [32]. Para que a adesão ocorra, a fibra e a matriz devem ser colocadas em contato íntimo, sendo que a molhabilidade, que depende do par fibra/matriz, pode ser considerada como um precursor essencial da adesão. Outros mecanismos relacionados às características do par fibra/matriz é a ligação eletrostática e ligação química [9]. Estes mecanismos, intrinsicamente relacionados aos pares de materiais que formam uma ligação, podem justificar a existência de tantas diferenças dos valores de tensão cisalhante interfacial para as diferentes matrizes poliméricas em um mesmo tipo de fibra e em fibras diferentes.

Quanto ao comportamento apresentado pelas curvas tensão x deformação nos ensaios de arrancamento, a Figura 11a mostra uma curva típica de um caso onde houve escorregamento da fibra da cápsula polimérica, apresentando como consequência, um baixo valor da tensão de tração e um patamar na parte superior da curva, mostrando o momento do desacoplamento da fibra, indicando que neste ponto não haveria uma efetiva transmissão de carga da matriz para a fibra [15], embora tenham sido observadas pequenas quantidades de resina aderidas na fibra (Figura 12a). De acordo com ZARGES et al. [13], à medida que o comprimento de embutimento da fibra aumenta, a carga necessária para o arrancamento da fibra também aumenta, o que justifica tensões mais altas nos ensaios onde o comprimento de embutimento é maior que o valor de $l c$ determinado. Quando um compósito reforçado com fibra vegetal é tracionado, a contração de Poisson da fibra supera o efeito da pressão normal da matriz na fibra, reduzindo a tensão de cisalhamento interfacial por atrito para uma mesma tensão aplicada e um comprimento de desacoplamento da interface fibra/matriz muito mais longo. Esta contração pode ser verificada na Figura 16a onde é possível observar que a fibra se separou da matriz ao longo de seu perímetro. Assim, a transferência de cargas entre a fibra e a matriz diminui devido à menor tensão de cisalhamento por atrito interfacial, levando a menos cargas transportadas pela matriz e poderá haver alguma quantidade de deslizamento da fibra dentro da matriz antes da ruptura catastrófica da fibra fora da matriz polimérica [31,33], o que poderia justificar o comportamento observado na Figura 11b, onde se observou na parte superior da curva, um trecho onde a relação tensão $\mathrm{x}$ deformação é diferente do restante da curva e diferente também do comportamento típico observado na curva da Figura 7 para a resistência da fibra. Outra explicação para o comportamento observado na Figura $11 \mathrm{~b}$ está no fato de que uma das formas de falha das fibras vegetais é por cisalhamento nos planos em que a carga se encontra e, neste caso, a fratura por cisalhamento pode causar a delaminação entre as camadas da fibra, provocando algum escorregamento [34], conforme observado na trica longitudinal da fibra mostrada na Figura $16 \mathrm{~b}$. 


\subsection{Caracterização mecânica das resinas - Ensaio de Tração}

Comparando-se a Tabela 7 com os resultados dos ensaios de arrancamento, observa-se que a ordem de resistência das resinas é a mesma da adesão entre fibra e matriz, ou seja, a resina de epóxi que apresentou maior adesão com a fibra foi a que teve maior resistência média à tração, seguido pela resina de poliéster isoftálico e por último a resina de poliéster ortoftálico, que também apresentou a menor aderência à fibra.

Outra característica importante apresentada na Tabela 7 é que, além da resina epóxi ter a maior resistência à tração, também apresentou maior alongamento, mostrando sua maior capacidade de se deformar plasticamente que as outras resinas estudadas. Além disso, foi a única resina que apresentou alongamento maior que o da fibra. Entretanto, apresentou um menor limite de escoamento e um maior módulo elástico, indicando menor capacidade de se deformar elasticamente. Estas características indicam que o epóxi tem a capacidade de gerar compósitos mais maleáveis, mais resistentes e com maior capacidade de acomodar o movimento da fibra dentro da matriz.

\subsection{Caracterização mecânica dos compósitos - Ensaio de Tração}

A Tabela 8 mostra que a matriz de epóxi foi a que promoveu uma maior resistência à tração, seguida pela matriz de poliéster isoftálico e, por fim, pela matriz de poliéster ortoftálico, mesma sequência da resistência das resinas e da adesão entre fibra e matriz. Observou-se também que, em todos os casos, a resistência dos compósitos ficou abaixo da resistência da matriz.

Esta redução da resistência dos compósitos em relação à resistência da matriz, é explicada por MONTEIRO et al. [29], que sugerem que para fibras de seção circular, se for assumido que a interface fibra/matriz é formada por uma matriz polimérica cobrindo semicilindros de fibras em contato entre si, limitando a penetração do polímero entre as fibras e criando concentradores de tensão, isto poderia reduzir em algumas vezes a resistência esperada do compósito. Isto porque parte da tensão aplicada, que é transferida para a fibra, é usada para separar os filamentos antes da ruptura total. Com a elevação da fração volumétrica da fibra, até certo limite, esse efeito pode ser reduzido.

BARBOSA [6] verificou em seu estudo com compósitos de fibra do pecíolo da folha do buriti em matriz de epóxi, que com uma fração volumétrica de $10 \%$ de fibra, a resistência do compósito ficou abaixo daquela encontrada na resina sem adição de fibra, e que somente acima de 10\% de fibra o compósito apresentou resistência à tração maior que o da matriz de epóxi. Esse comportamento ocorreu para todas as matrizes usadas neste estudo, sendo que a matriz de poliéster isoftálico foi a que apresentou menor redução da resistência média à tração em relação à resistência da resina $(15,74 \%)$, seguida pela matriz de epóxi $(22,66 \%)$ e, por fim, pela matriz de poliéster ortoftálico $(41,85 \%)$.

Quanto ao comportamento mostrado na Figura 15, em um compósito de matriz polimérica, a falha por fratura se inicia nas fibras, enquanto a matriz continua a se deformar plasticamente. Após a ruptura das fibras, a matriz continua a se deformar plasticamente até atingir sua capacidade de deformação plástica e se rompe também. Isso ocorre porque a capacidade da matriz polimérica de se deformar até a ruptura é maior que a da fibra [26]. Porém, analisando-se as tabelas 3 e 7, verificou-se que as fibras da folha de buriti apresentaram um alongamento médio na ruptura $(3,6 \%)$ maior que aqueles obtidos pelas resinas de poliéster isoftálico $(2,54 \%)$ e ortoftálico $(3,37 \%)$, e isso pode ter provocado a falha da matriz polimérica antes da ocorrida na fibra. No caso da matriz de epóxi, como seu alongamento médio na ruptura $(6,55 \%)$ foi maior que o da fibra, em nenhum corpo de prova houve ruptura da matriz antes da ruptura da fibra. Como houve grande aderência do poliéster isoftálico na fibra, o compósito criado com essa matriz proporcionou um alongamento médio na ruptura mais alto que o dos elementos individuais $(4,10 \%)$, mesmo com uma baixa fração volumétrica.

\section{CONCLUSÕES}

As fibras das folhas de buriti apresentaram limite de resistência à tração médio semelhante e até superior ao de outras fibras de origem vegetal, contudo com uma densidade menor, podendo proporcionar compósitos com uma maior relação resistência/peso.

Das resinas estudadas para uso como matriz polimérica, a de epóxi foi a que mostrou maior afinidade com a fibra da fola de buriti, proporcionando um pequeno comprimento crítico de adesão, inferior a 1,0 mm, e uma alta tensão de cisalhamento interfacial, superior a da maioria dos compósitos de fibras lignocelulósicas em matriz polimérica, demonstrando uma alta capacidade de adesão entre a fibra e a matriz, podendo, assim, proporcionar a produção de compósitos mais resistentes. A resina de poliéster isoftálico também proporcionou uma boa aderência na fibra, porém com uma menor capacidade de se deformar. A resina de poliéster ortoftálico não proporcionou uma boa aderência na fibra. 
A resina de epóxi apresentou maior resistência à tração, menor tensão de escoamento, mas com maior módulo elástico, e maior alongamento na ruptura, podendo proporcionar compósitos mais maleáveis e mais resistentes. A resina de poliéster isoftálico, dentro das resinas testadas, apresentou o segundo maior módulo elástico e resistência à tração, proporcionou uma maior tensão de escoamento, porém com menor alongamento na ruptura, podendo proporcionar compósitos mais rígidos, mas menos resistentes que os de epóxi. A resina de poliéster ortoftálico apresentou valores inferiores às demais na tensão máxima e no módulo de elasticidade, proporcionou limite de escoamento superior ao do epóxi e alongamento na ruptura maior que a do poliéster isoftálico, indicando ser a menos indicada para ser usada como matriz para compósitos com fibras da folha de buriti.

Dos compósitos produzidos, a matriz de epóxi foi a que apresentou maior potencial para gerar materiais fortes, maleáveis e leves. A matriz de poliéster isoftálico, devido à alta aderência na fibra, também poderá gerar compósitos fortes e leves, embora inferiores em resistência à tração em relação aos de matriz de epóxi, porém mais baratos.

Os resultados desta pesquisa mostraram que a fibra da folha de buriti tem um bom potencial para gerar compósitos fortes e leves.

\section{AGRADECIMENTOS}

Ao Laboratório de Materiais e Ensaios Mecânicos da Faculdade de Engenharia Mecânica (UniRV) e ao Laboratório de Estruturas e Materiais da Faculdade de Engenharia Civil (UniRV) pela disponibilização dos equipamentos nos ensaios mecânicos. À Universidade de Rio Verde e ao CNPq pelo apoio financeiro através de bolsas concedidas aos pesquisadores.

\section{BIBLIOGRAFIA}

[1] WEARN, Y.N., MONTAGNA, L.S., PASSADOR, F.R., "Compósitos de fibra de coco/LDPE: efeito do tratamento superficial das fibras de coco em compósitos verdes”, Revista Matéria, v. 25, n. 1, Dez.2020.

[2] MONTEIRO, S.N; LOPES, F.P.D.; BARBOSA, A.P.; et al., "Natural lignocellulosic fibers as engineering materials - an overview", The Minerals, Metals \& Materials Society and ASM International, v. 42A, pp. 2963-2974, Oct. 2011.

[3] KNUTH, F.A, GONÇALVES, M.R.F., GATTO, D.A., et al., "Feixes de fibras lignocelulósicas refinadas mecanicamente em compósitos cimentícios para avaliação da resistência à tração", TECNO-LÓGICA, v. 21, n. 2, pp. 46-50, Jul./Dez. 2017.

[4] SAHA, P., CHOWDHURY, S., ROY, D., et al., "A brief review on the chemical modifications of lignocellulosic fibers for durable engineering composites", Polymer Bulletin, v. 73, issue 2, pp. 587-620, Feb. 2016.

[5] DEMOSTHENES, L.C.C., NASCIMENTO, L.F.C., MONTEIRO, S.N, et al., "Thermal and structural characterization of buriti fibers and their relevance in fabric reinforced composites", Journal of Materials Research and technology, v. 9, issue 1, pp. 115-123, Jan./Feb. 2020.

[6] BARBOSA, A.P. "Características estruturais e propriedades de compósitos poliméricos reforçados com fibras de buriti”. Tese de D.Sc., Universidade Estadual do Norte Fluminense, Campos dos Goytacazes, RJ, Brasil, 2011.

[7] BARBOSA, A.P., ALTOÉ, G.R., LOIOLA, R.L., et al., "Bending Mechanical Behavior of Epoxy Matrix Reinforced with Buriti Fiber”, Materials Science Forum, v. 869, pp. 243-248, Aug. 2016.

[8] GOWDA, T.G.Y., SANJAY, M.R., BHAT, K.S., et al., "Polymer matrix-natural fiber composites: an overview", Cogent Engineering, v. 5, n. 1, pp. 1-13, Mar. 2018.

[9] PICKERING, K.L., EFENDY, M.G.A., LE, T.M., “A review of recent developments in natural fibre composites and their mechanical performance”, Composites: Part A, v. 83, pp. 98-112, Sep. 2015.

[10] REVOL. B.P., THOMASSEY, M., RUCH, F., et al., "Single fibre model composite: Interfacial shear strength measurements between reactive polyamide- 6 and cellulosic or glass fibres by microdroplet pullout test”, Composites Science and Technology, v. 148, pp. 9-19, Aug. 2017.

[11] SOOD, M., DWIVEDI, G., "Effect of fiber treatment on flexural properties of natural fiber reinforced composites: A review”, Egyptian Journal of Petroleum, v. 27, pp. 775-783, Nov. 2017. 
[12] GRAUPNER, N., RÖßLER, J., ZIEGMANN, G., MÜSSIG, J., "Fibre/matrix adhesion of cellulose fibres in PLA, PP and MAPP: a critical review of pullout test, microbond test and single fibre fragmentation test results", Composites: Part A, v. 63, pp. 133-148, Aug. 2014.

[13] ZARGES, J.C., KAUFHOLD, C., FELDMANN, M., et al., "Single fiber pull-out test of regenerated cellulose fibers in polypropylene: an energetic evaluation", Composites: Part A, v. 105, pp. 19-27, Feb. 2018.

[14] ZHOU, J., LI, Y., LI, N., et al., "Interfacial shear strength of microwave processed carbon fiber/epoxy composites characterized by an improved fiber-bundle pull-out test", Composites Science and Technology, v. 133, pp. 173-183, Sep. 2016.

[15] OUSHABI, A., "The pull-out behavior of chemically treated lignocellulosic fibers/polymeric matrix interface (LF/PM): a review", Composites Part B, v. 174, pp. 1-12, Oct. 2019.

[16] MONTEIRO, S.N., D’ALMEIDA, J.R.M., "Ensaios de pullout em fibras lignocelulósicas - uma metodologia de Análise", Revista Matéria, v. 11, n. 3, pp. 189-196, Set. 2006.

[17] ASTM D638-14, Standard Test Method for Tensile Properties of Plastics, West Conshohocken, PA, United States, ASTM International, 2014.

[18] ASTM D3039, Standard Test Method for Tensile Properties of Polymer Matrix Composite Materials, West Conshohocken, PA, United States, ASTM International, 2000.

[19] VIEIRA, C.S., MARQUES, S.P.C. "Influência de interfases sobre a condutividade térmica efetiva de compósitos periódicos reforçados por fibras", Revista Matéria, v. 24, n. 3, Set. 2019.

[20] PASSOS, M.A.B., MENDONÇA, M. S., "Epiderme dos segmentos foliares de Mauritia flexuosa L. f. (Arecaceae) em três fases de desenvolvimento", Acta Amazônica, V. 36, n. 4, pp. 431-436, 2006.

[21] KELLY, A., TYSON, W.R., High Strength Materials, Nova York, Wiley, 1965.

[22] LAU, K.T., HUNG, P.Y., ZHU, M.H., et al., "Properties of natural fibre composites for structural engineering applications", Composites Part B, v. 136, pp. 222-233, Mar. 2018.

[23] SANJAY, M.R., MADHU, P., JAWAID, M., et al., "Characterization and properties of natural fiber polymer composites: a comprehensive review", Journal of Cleaner Production, v. 172, pp. 566-581, Jan. 2018.

[24] YULIANTO, PUTRI, D.N., PERDANI, M.S., et al., "Effect of cellulose fiber from sorghum bagasse on the mechanical properties and biodegradability of polylactic acid", Energy Reports, v. 6, s. 1, pp. 221-226, Feb. 2020.

[25] ORNAGHI JÚNIOR, H.L., MORAES, A.G.O., POLETTO, M., et al., "Chemical composition, tensile properties and structural characterization of buriti fiber", Cellulose Chemistry and Technology, v. 50, n. 1, pp. 15-22, Jan. 2016.

[26] CALLISTER JR. W.D., RETHWISCH, D.G., Ciência e Engenharia de Materiais - uma Introdução, 9 ed, Rio de Janeiro, LTC, 2018.

[27] LI, W., SIGLEY, J., PIETERS M., et al., "Fibrin Fiber Stiffness Is Strongly Affected by Fiber Diameter, but Not by Fibrinogen Glycation”, Biophysical Journal, v. 110, issue 6, pp. 1400-1410, Mar., 2016.

[28] MARGEM, J.I., MONTEIRO, S.N., GOMES, V.A., et al., "Pullout tests behavior of epoxy matrix reinforced with malva fibers", Characterization of Minerals, Metals, and Materials, pp. 457-463, Feb. 2015.

[29] MONTEIRO, S.N., LOPES, F.P.D., FERREIRA, A.S. et al., "Natural-fiber polymer-matrix composites: cheaper, tougher, and environmentally friendly", JOM, v. 61 n. 1, pp. 17-22, Jan. 2009.

[30] IBRAHIM, H., MEHANNY, S., DARWISH, Lamis, et al., "a comparative study on the mechanical and biodegradation characteristics of starch-based composites reinforced with different lignocellulosic fibers", Journal of Polymers and the Environment, v. 26, issue 6, pp. 2434-2447, Jun. 2018.

[31] ZHANG, Z., LI, Y., FU, K., et al., "Determination of interfacial properties of cellulose nanocrystalmodified sisal fibre in epoxy by cyclic single-fibre pull-out", Composites Science and Technology, v. 193, pp. 1-8, Jun. 2020.

[32] ARIAWAN, D., ISHAK, Z.A.M., SALIM, M.S., et al., "Wettability and interfacial characterization of alkaline treated kenaf fiber-unsaturated polyester composites fabricated by resin transfer molding", Polymer Composites, v. 38, issue 3, pp. 507-515, Mar. 2017.

[33] LONGBIAO, L. "Effect of fiber poisson contraction on matrix multicracking evolution of fiberreinforced ceramic-matrix composites", Applied Composite Materials, v. 22, issue 6, pp. 583-598, Dec 2015. 
[34] TAN, Z.E., LIEW, C.K., YEE, F.C., et al., "Oil palm empty fruit bunch fibres and biopolymer composites: possible effects of moisture on the elasticity, fracture properties and reliability", Green Biocomposites Manufacturing and Properties, pp. 271-291, Nov. 2016.

\section{ORCID}

Warley Augusto Pereira

Igor Ceron

Matheus Souza e Silva

Marcos Paulo Chaves de Freitas

Edson Roberto da Silva

Fabíola Medeiros da Costa https://orcid.org/0000-0002-6704-6762

https://orcid.org/0000-0002-3184-9184

https://orcid.org/0000-0001-9915-7953

https://orcid.org/0000-0003-0942-3221

https://orcid.org/0000-0002-3430-4462

https://orcid.org/0000-0002-0845-4096 